\title{
Deconstructing the Superblock:
}

\section{Universal Solutions vs. Cultural Specificity in Chinese Urban Planning}

by

Steven Gajer

A thesis submitted to the Faculty of Graduate and Postdoctoral Affairs in partial fulfillment of the requirements for the degree of

Master of Architecture

in

M. Arch. (Professional)

Carleton University Ottawa, Ontario

$$
\text { (c) } 2015
$$

Steven Gajer 
Since the introduction of economic reforms in 1978, an astonishing 300 million Chinese have relocated to cities. As a result, the built-up area of China's cities has expanded more than fourfold. The build-out of the periphery is occurring at the scale of the neighbourhood, with individual developers controlling massive parcels of land. More often than not, the neighborhoods they produce consist of repetitive towers corralled into gated superblocks that are separated by wide, arterial streets. The very embodiment of expediency, these tower ensembles also adhere closely to modernist principles of urban planning, many of which have been challenged in the West.

The practice of aggregating housing into large enclosed ensembles has a long history in China. The preponderance of shared, semi-private space over explicitly public or private space is uniquely Chinese. It stands in contrast to traditional Western patterns of urbanization that emphasize the individual and enshrine private ownership. Nonetheless, Reform Era tower ensembles have been criticized for being homogeneous, car-centric, and lacking human scale - problems that may threaten their long-term sustainability and the vitality of the larger urban environments they produce. Attempts to apply Western precepts to the reinvention of the Chinese superblock frequently do not take into account particularities of the Chinese context. This thesis explores an adapted approach to urban development that is informed by the Western experience while remaining rooted in China's urban traditions. 
Abstract

Illustrations

Introduction

Urbanization in China

Scope of Thesis

Chapter 1

The Superblock in Reform Era China

1.1 Characteristics of Urban Development in Reform

$$
\text { Era China }
$$

1.2 Influences on Superblock Development

1.3 Disadvantages of Chinese Superblock Development

Chapter 2

The Superblock as Indigenous Chinese

\section{Urban Form}

2.1 Historical Cellular Urban Forms in China

2.2 Continuities and Divergences among Historical Urban Forms

Chapter 3

The Superblock in the West 
Chapter 4

\begin{tabular}{|c|c|}
\hline & $\begin{array}{l}\text { 4.1 Reaction to Superblock Development in the } \\
\text { West: New Urbanism }\end{array}$ \\
\hline & $\begin{array}{l}\text { 4.2 New Urbanism as an Alternative to Chinese } \\
\text { Superblock Planning }\end{array}$ \\
\hline & $\begin{array}{l}\text { 4.3 The Future of the Superblock: Towards an } \\
\text { Adapted Approach to Urban Planning in Chine }\end{array}$ \\
\hline & 4.4 An Adapted Model of Urban Development \\
\hline Chapter 5 & Design Proposal \\
\hline & 5.1 Deconstructing the Superblock \\
\hline & 5.2 The Adapted Superblock \\
\hline nclusion & \\
\hline & $\begin{array}{l}\text { Learning from the West: The Validity of a Hybrid } \\
\text { Approach }\end{array}$ \\
\hline
\end{tabular}


Introduction

Pudong, Shanghai: 1987 to 2013

Urban growth in Reform Era China 2

Urban growth in Reform Era China

Superblock Development in China 3

Superblock Development in China

\section{Chapter 1}

Superblock Development in China 5

Superblock as "tombstone urbanism"

New York City at $14^{\text {th }}$ Street in Manhattan 6

The streetscape of Chinese superblock development 6

Aerial Satellite View of Manhattan's East Side 6

Aerial Satellite View of Beijing's Second Ring Road 6

Cellular vs. Street-Oriented Urbanism 6

A residential enclave in China 7

Interior open space of a residential enclave in China 7

Hutong 8

Lilong

Danwei 8

Influence of Solar Exposure on Urban Form 9

Superblock as "tombstone urbanism"

North American suburban development 11

Standard Reform Era Superblock

Chapter 2

Hutong 14

Lilong 14

Gating and laneways of the lilong 15 
Interior roads of the danwei

Microdistrict Planning System

Neighbourhood Unit, Clarence Perry

Lilong

Danwei

Chinese Superblock

Laneways of the lilong

Interior courtyard of superblock development

\section{Chapter 3}

Plan Voisin, Le Corbusier, 1925

"From the Block to the Bar", Walter Gropius, 1925

Neighbourhood Unit, Clarence Perry

Radburn Model, Clarence Stein and Henry Wright

Stuyvesant Town and Peter Cooper Village, New York, 1947

Conditions for Successful Cities according to Jane Jacobs

Pruitt-Igoe, St-Louis, 1954

Destruction of Pruitt-Igoe, St-Louis, demolished 1972

Concept for spacing of residential slabs, Walter Gropius, 1929

Aerial view of suburb to the south of Beijing

The Superblock in its Urban Context

"From the Block to the Bar", Walter Gropius, 1925

Influence of Solar Exposure on Urban Form

\section{Chapter 4}




\section{Chapter 5}

New Urbanist Planning vs. Chinese Superblock

Variation of Western and Chinese Standard Models to Achieve Hybrid Urban Form

Adapted Model vs. Chinese Superblock

Adapted Model as Hybrid of Western and Chinese Superblock Planning 
Urbanization in China

Long referred to as "the sleeping giant," China's economy has grown exponentially in the past thirty years. This growth has been accompanied by rapid urbanization. Since economic reforms were introduced in 1978 , 300 million people have migrated to cities from rural areas. Despite this, however, only $54 \%$ of China's population lives in cities, a significantly lower percentage than in other developed countries. As such, Chinese cities are expected to accommodate an additional 400 million people by 2050 . How urban growth is managed and the form that development takes will have important consequences on China's economy and longterm social equilibrium.

The unique political and economic context of Reform Era China has shaped the Chinese city in the past several decades. Both the strong role of the state and market forces have influenced the form that urbanization has taken. Public control of land has also greatly facilitated the process of redeveloping and converting land, allowing China to meet the aggressive targets it set for urbanization in the Reform Era. Large-scale development - typically at the neighbourhood scale - is favoured, with infrastructure largely constructed in advance of growth.

Since economic reforms began in 1978 , foreign investment has played an increasingly important role in the development of Chinese cities. This is most evident in cities that were designated as Special Economic Zones (SEZ's) after reform. Shenzhen, for example, was a
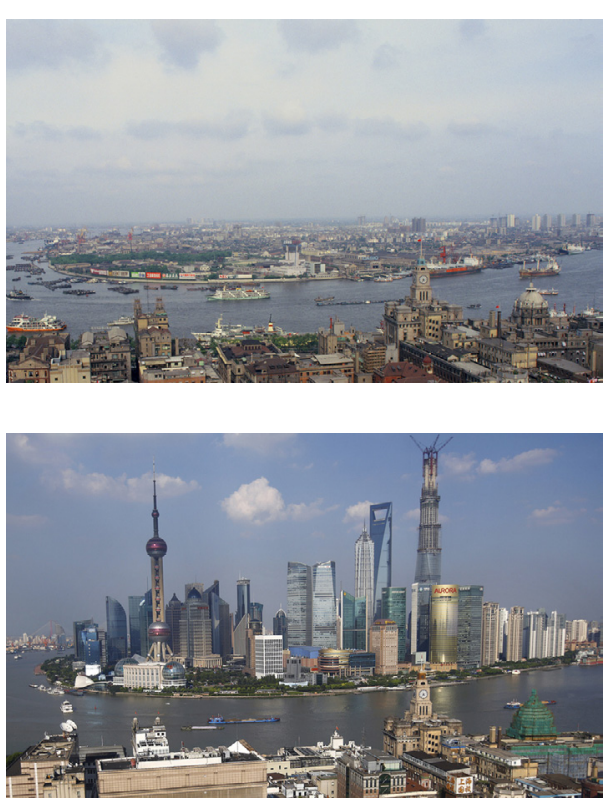

The development of Pudong on the east side of the Huangpu River in Shanghai occurred within 30 years, after economic reforms began in 1978 . 
town of 70,000 residents when it was designated as an SEZ in 1980; its population expanded to 7 million by $2000 .{ }^{1}$ This growth largely reflects a massive influx of workers attracted by salaries, housing and educational opportunities that became available as the city was opened to the global market.

Economic reforms and the introduction of market forces into the country have been accompanied by decentralization and devolution of power to lower levels of government. While entirely beholden to the central government in the decades following WWII, municipal governments have assumed greater responsibility for urban planning and development in recent decades. ${ }^{2}$ Municipalities have become entrepreneurial agents promoting growth and courting investment. ${ }^{3,4}$ While the state retains ownership of all urban land, land-use rights were introduced in $1988 .{ }^{5}$ City governments transfer development rights on state-owned land in exchange for lucrative lease agreements: 40 years for commercial, 50 years for industrial, and 70 years for residential development. ${ }^{6}$ Unable to raise money through property taxes, municipal governments rely on land leases to fund social services. Land is also used as collateral for loans for infrastructure improvements. ${ }^{7}$ As such, there are strong financial incentives for promoting development. All of these factors play into the shape that urbanization takes.

Over the course of the three-decade Reform Era the built-up area of Chinese cities have expanded fourfold. ${ }^{8}$ At the same time migration to 
cities has been managed by China's system of household registration the so-called hukou system. Hukou reform, which will enable people to move more freely between rural and urban areas, is imminent. As such, future urbanization will address the approximately 250 million people of rural origin who have no access to social services in the cities in which they reside. These are known as the liudong renkou or floating populations.

Given what lies ahead, it is both timely and relevant to evaluate the success of the methods that have been deployed to accommodate growth in recent decades. Of particular interest is whether current approaches to the conversion and build-out of the urban periphery are extensible, flexible and resilient enough to contribute to the long-term success of China's cities.

\section{Scope of Thesis}

This thesis examines what has become the default module of urban development in China, namely superblocks of repetitive, residential towers, questioning its appropriateness for future growth. Concepts of streetoriented urbanism in the West, as differentiated from cellular urban development in China, will be used as a counterpoint to frame the analysis. Historical Chinese urban forms that have been developed in enclosed superblocks and superblock planning in the West will be analyzed in comparison to current development in China to inform criteria for a hybrid approach to development. Graphic analysis and diagrams will be
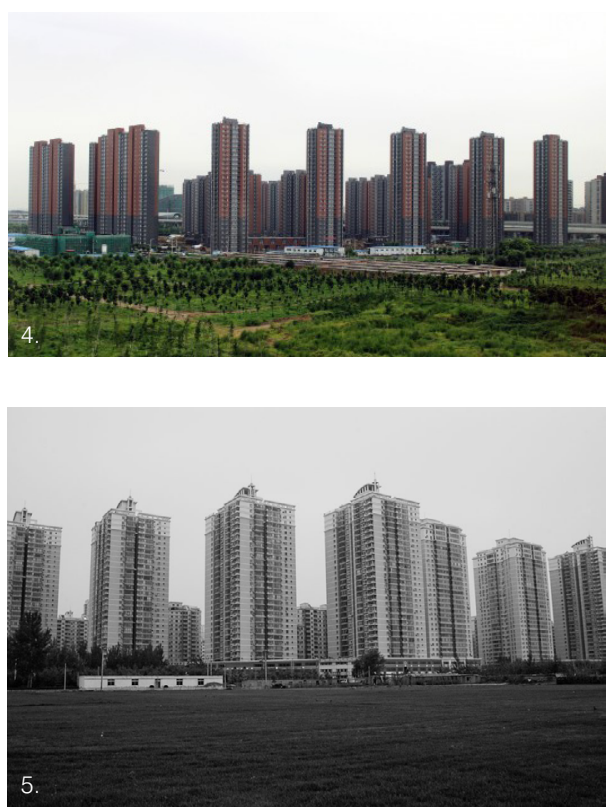

The default module of urban development in China: superblocks of repetitive, residential towers. 
used to establish and compare the characteristics of urban forms. This comparison will be incorporated into a design proposal for an adapted urban model for Chinese cities.

\section{Structure}

Chapter 1 analyzes the origins and evolution of Chinese urban development, discussing formal, political and cultural influences. The chapter raises issues with China's current approach to superblock development, questioning its resilience. Further analysis is undertaken in Chapter 2 to better understand why the Chinese superblock takes the form it does. It identifies continuities and differences between precedents and current development practices, considering how a reconsideration of precedents might inform a more sustainable and culturally resonant model for future development. Chapter 3 outlines Western approaches to the superblock, including critiques that have been levelled against it. It then compares Chinese and Western approaches to superblock planning to assess the ultimate resilience of superblock development in the Chinese context.

Chapter 4 presents current ideals and approaches to sustainable urbanism in the West and questions their applicability to the Chinese context in response to ongoing environmental and social concerns with cellular development. The concept of a hybrid urban form is introduced, incorporating both Western and Chinese planning concepts. This is followed by a list of characteristics and criteria for this hybrid model. Chapter 5 presents various iterations of hybrid forms, one of which is developed in greater detail. notes

1. Asian Development Bank, Urbanization and Sustainability in Asia: Case Studies of Good Practice (Manila: Asian Development Bank, 2006), 122

2. Daniel Benjamin Abramson, "Urban Planning in China Continuity and Change," Journal of the American Planhing Association [H.W.Wilson - SSA] 72 (2) (2006). 3. De Wang et. al., "Urban infrastructure financing in
Reform-Era China," Urban Studies 48 (14) (2011): 2975998.

4. Samuel Liang, "Planning and its Discontents: Contradictions and Continuities in Remaking China's Great Cities, 1950-2010," Urban History 40 (3) (2013): 543

5. You-tien Hsing, The Great Urban Transformation: Politics of Land and Property in China (Oxford: Oxford University Press, 2010).

6. Abramson, "Urban Planning in China", 204.

7. This is done indirectly through local government investment companies or LICs. See Tom Miller, China's Urban Billion (London, New York: Zed Books, 2012): 101 8. Tom Miller, China's Urban Billion (London, New York: Zed Books, 2012): 80. 
This chapter explores the origins, evolution, and characteristics of

Reform Era urban development in China. Consisting of large enclosed cells, the current approach differs significantly from the finer grained, street-oriented development of traditional Western cities. While strikingly modern and circumscribed by expediency, current development patterns also reflect longstanding, culturally ingrained traditions. In spite of this, however, current approaches may prove less than resilient in the long run.

\section{Characteristics of Urban Development in Reform Era China} Urban development in the last thirty years has been largely characterized by large parcels of residential towers separated by wide thoroughfares. Massive in comparison to traditional Western urban blocks, the basic unit of urban development is the superblock - ranging in size from 6 to 35 hectares - leased by the municipal government and built out by a housing developer. Served by an internal network of roads and open spaces, these blocks, to which access is carefully restricted, function largely independently of the rest of the city. So predominant is this form of development that vast areas of the urban landscape are characterized by "tombstone urbanism,": repetitive, shallow rows of residential slabs separated by large, uninterrupted spaces.

This cellular pattern of large-parcel urbanism differs significantly from the street-oriented development characteristic of traditional Western
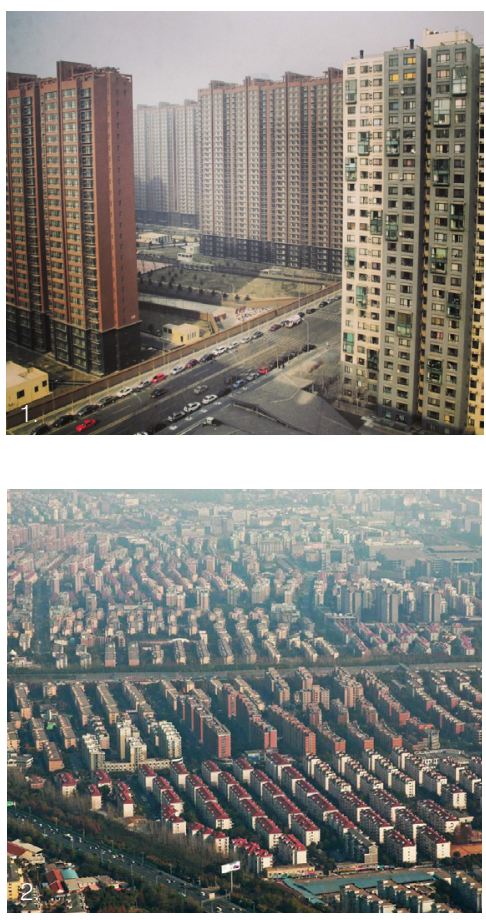

The land leasing system of urban develop ment in Reform Era China has led to much of China's urban landscape to be characterized by "tombstone urbanism": repetitive, shallow rows of residential slabs separated by large uniterrupted spaces. 
cities and what is now widely considered to be "good" urban form. Given the prevailing structure of private property, Western cities are most often developed one lot - or at most one block - at a time. This is also true in Asian cities like Tokyo. By contrast, urban development in Reform-Era China, is frequently undertaken at the scale of the neighbourhood - a single parcel of six hectares or more. The result is a much larger grain of urban fabric with larger blocks and wider, less frequent streets. As a result large amounts of urban space are internalized within superblocks, which are separated from each other by boulevards and traffic arteries. The connection between these privatized enclaves and the public realm of the city occurs at gates designed to keep out non-residents..$^{1,2}$ There is an abrupt distinction between the realm of the street and the realm of the block.

While in a Western, street-oriented context, urban amenities would be incorporated into a continuous public realm, the scale of the Chinese superblock is so large that a number of typically public urban elements are integrated within it. ${ }^{3}$ While the developer typically provides pedestrian paths, parking, a network of vehicular paths for service and emergency vehicles, gathering spaces, playgrounds, and parks, the municipality frequently contributes a school. In contrast to traditional Western urbanism, where public streets, parks and plazas function as spaces for social interaction, large amounts of social space in Chinese cities are internalized within block and reserved for residents. This focuses many aspects of urban life into the block as opposed to onto the street.
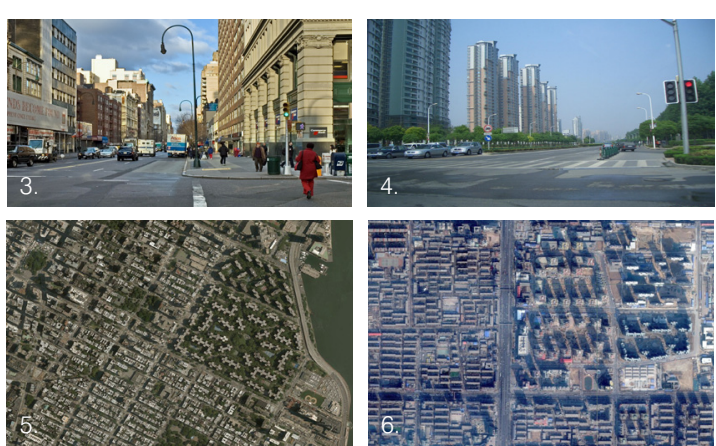

The scale of development in Manhattan (left) leads to a very different grain of fabric than that of Beijing (right) with its larger blocks and wider, less frequent streets.

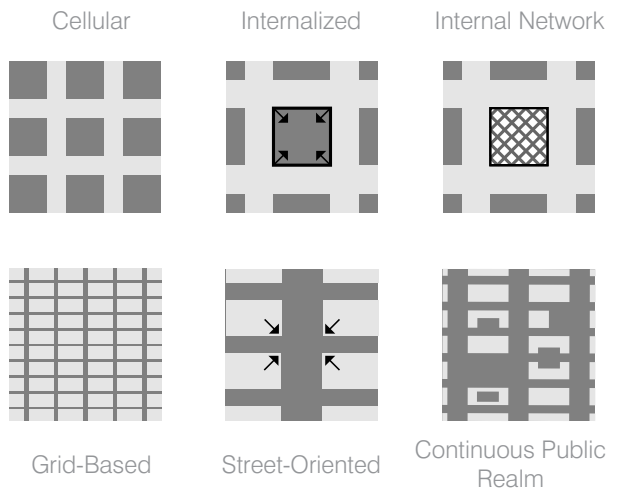

Charactertistics of cellular development in China vs. street-oriented development in the West.

Cellular vs. Street-Oriented Urbanism 
The scale of parcels being so large, urban development in ReformEra China more closely resembles suburban development in the West. Comparable to the scale of the typical suburban development parcel, these superblocks are, in effect, high-density gated subdivisions. Both possess limited entry and exit points and limited connections to adjacent subdivisions. That said, the superblock approach to urban design was deployed for post-war urban redevelopment projects in cities in the West. Projects like Pruitt-Igoe in St. Louis, Stuyvesant Town in Manhattan, and Churchill Gardens in London bear strong formal similarities to the ubiquitous ensembles of high rises encircling cities in China. As opposed to typical lot-scale development in these cities which was oriented toward the street, these projects are centred on the superblock and, like Chinese urban form, represent a more inward-looking form of urbanism.

\section{Influences on Superblock Development}

The superblock has proven to be both efficient and economical in accommodating the considerable urban growth that has occurred since the 1980s. Development at the scale of the superblock has enabled the expedient expansion and redevelopment of cities by dividing the responsibility for development to the private sector. As land leases are the primary mechanism by which local governments generate revenue for social services, they are motivated to convert large tracts of land on the urban periphery from rural to urban use. ${ }^{4}$ Services are extended and the land is subdivided into large parcels to be leased to developers.
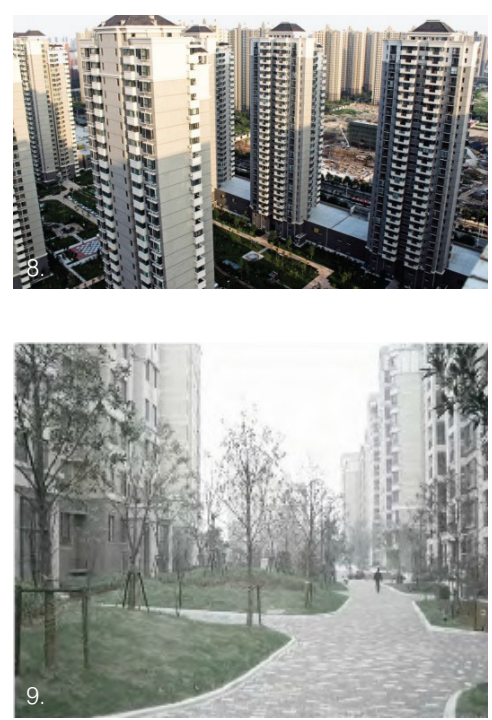

The scale of development in China is so large that a variety of urban elements are incoroporated within the large amounts of open space in its confines. 
Standards regarding open space coupled with aggressive density targets help explain why high-rise slabs are almost universally favoured for residential development. The speed and efficiency with which projects are realized, however, coupled with the size of parcels, frequently results in repetitive, visually similar environments.

Buildings are pragmatic both in construction and appearance. Indeed repetitive towers dropped on to large-scale parcels are the very embodiment of expediency. As such, there is little question that ReformEra development reflects the scale and dizzying pace at which urbanization is occurring in China. In other respects, however, current development patterns are also consistent with longstanding approaches to the provision of housing in China - namely a tradition of large, enclosed urban blocks.

While towers are relatively new to the Chinese residential landscape, Chinese cities have followed a cellular pattern of development throughout time. ${ }^{5,6,7}$ Urban housing forms such as the hutong - a traditional residential neighbourhood of courtyard houses embedded into a tight network of laneways - and the lilong - laneway housing comprised of parallel rows of attached houses - were aggregated into very large blocks and accessed via gated entry points along the commercial streets surrounding them. These patterns persisted into the middle of the $20^{\text {th }}$ century. Even urban development in 1950s and '60s, organized around the danwei or work unit, was also largely cellular in form. Work units were enclosed, self-sufficient neighbourhoods combining factories,

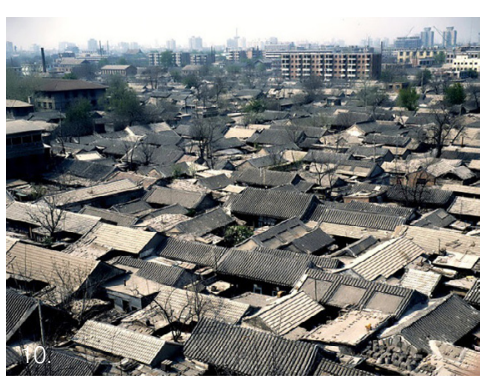

Hutong

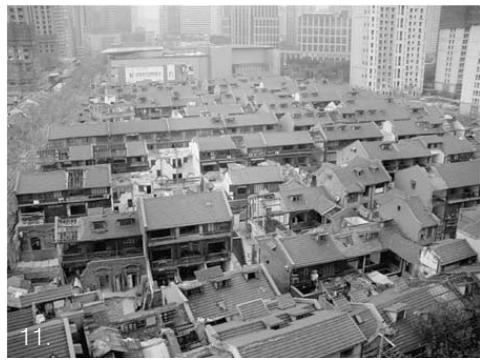

Lilong

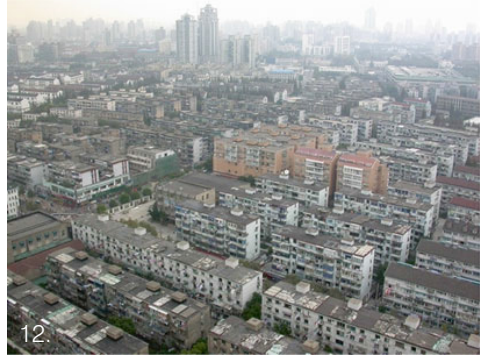

Danwei

Chinese cities have followed a cellular pattern of development throughout their history 
residences, schools and social services. Socialism in communist-era China was largely administered through state-run industries.

In this respect, the scale, inward focus, and cellular form of Reform Era development in China is consistent with indigenous traditions. ${ }^{8,9}$ Indeed the predilection for the large, gated urban blocks could be said to be cultural and that development at the scale of the neighbourhood reflects a more collectivist sensibility than in the West where individual rights and private property are enshrined. ${ }^{10}$ Gated along its perimeter, the contemporary Chinese superblock continues a longstanding concern for security and collectivism. Indeed, the development of cities in urban collectives - referred to as xiaoqu or "small districts" - is reflected in national planning codes. ${ }^{11}$

Throughout time urban development in China was also strongly shaped by the importance placed on solar exposure for housing units. In light of this, residential development has historically taken the form of shallow, repetitive rows of housing spaced to facilitate solar exposure. This concern continues to define the shape of contemporary development. Like the organization of urban housing in collectives, government regulations dictate that every unit receive a minimum of one hour of sunlight on the shortest day of the year. ${ }^{12}$ With the move from low-rise to high-rise housing, blocks of units have become increasingly widely spaced to maximize solar exposure and minimize shading.
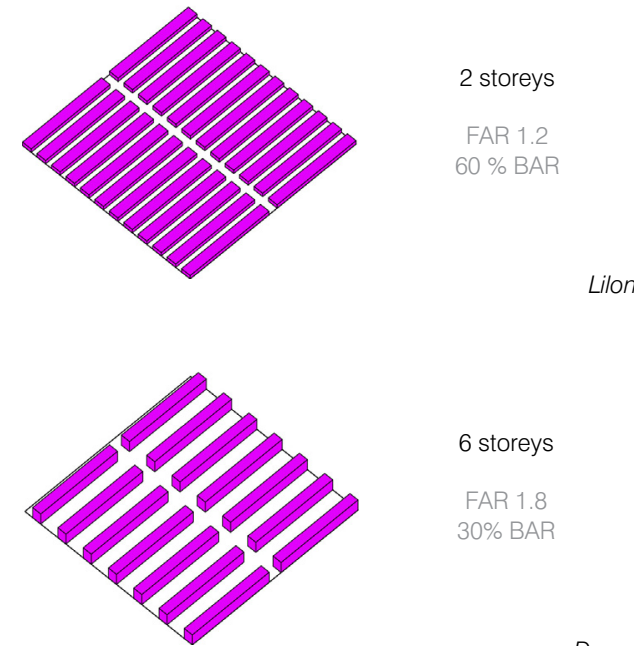

6 storeys FAR 1.8

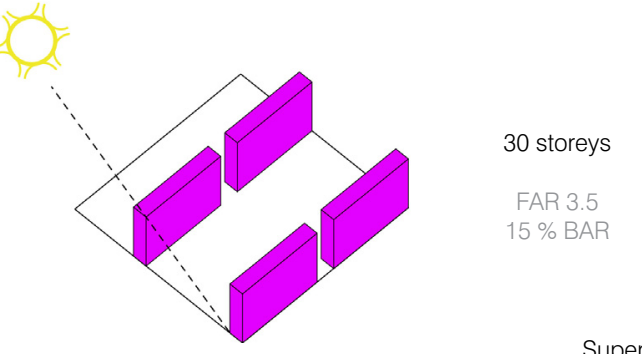

Superblock

With the move from low-rise to high-rise housing, blocks of units have become increasingly widely spaced to maximize solar exposure and minimize shading. A relationship between building height and lot coverage can be seen in comparing the configurations of the lilong, danwei, and superblock. As building size increases progressively in each era, the spacing of dwellings increases in order to maintain an acceptable level of solar exposure for all units. Therefore overall lot coverage, or built area ratio (BAR), decreases. 


\section{Disadvantages of Chinese Superblock Development}

Symptomatic of the scale and rapidity of change, displacement and modernization in China, a number of environmental and social issues have arisen in relation to this new generation of neighbourhood enclaves. However different in form and density, the newly minted urban landscapes in China suffer from many of the same issues and chal-

lenges as low-density suburban developments in North America - most notably homogeneity and car dependence.

The urban designer Peter Calthorpe, who is associated with New Urbanism, has contended that the form of development in China has had a significant negative environmental impact, referring to the superblock as a "weapon of mass urban destruction" in regards to its effect on a city's urban fabric. ${ }^{13} \mathrm{He}$ asserts that Chinese superblock planning is centred on car travel and as such exacerbates China's struggle with increasing automobile usage. As the contents of each Chinese superblock are largely the responsibility of a developer, they are principally residential in function and do not necessarily provide sufficient services to residents. Such development fosters increased car use by increasing the need for trips farther from the home. While residential developments in the city centre benefit from the proximity of services, many on the periphery do not, nor is the public transit as convenient or available on the periphery as it is in the core. The state currently has an interest in reducing car usage in Chinese cities. Several Chinese cities including Beijing and Shanghai have regulations in place to restrict the number of vehicle 
registrations and car use in their cities. The $12^{\text {th }}$ five-year plan includes a target to reduce carbon emissions by 17 percent by the end of $2015 .{ }^{14}$ The relation between the land use mix of a neighbourhood and carbon emissions in several Beijing neighbourhoods has been studied. ${ }^{15}$ Findings indicate that the more a neighbourhood is exclusively residential, the higher its carbon emissions. Due to its lack of functional diversity, the Chinese superblock development in its current form promotes greater car use by increasing need for travelling farther from the home.

The commodification of housing in the Reform Era reorganizes people by education and employment status. There is a direct relationship between where urban residents live and what they can afford.

Further, because they are largely at the discretion of the developer and pegged to what the target buyer can afford, the extent and type of amenities within a given development parcel vary with price point. ${ }^{16}$ This, too, contributes to social homogenization within blocks by sorting prospective residents both by what they can afford and according to the amenities they value. With the population already more spatially stratified due to the opening of housing to the market, cellular development exacerbates this by spatially isolating housing complexes from each other and the rest of the city through gating and enclosure. However, it is the unregulated commodification of housing development that is the cause of social segregation and not the gating, per se. ${ }^{17}$ Thus only in the Reform Era, in which housing is primarily determined by developers working within the evolving housing market, does the gating of residen-
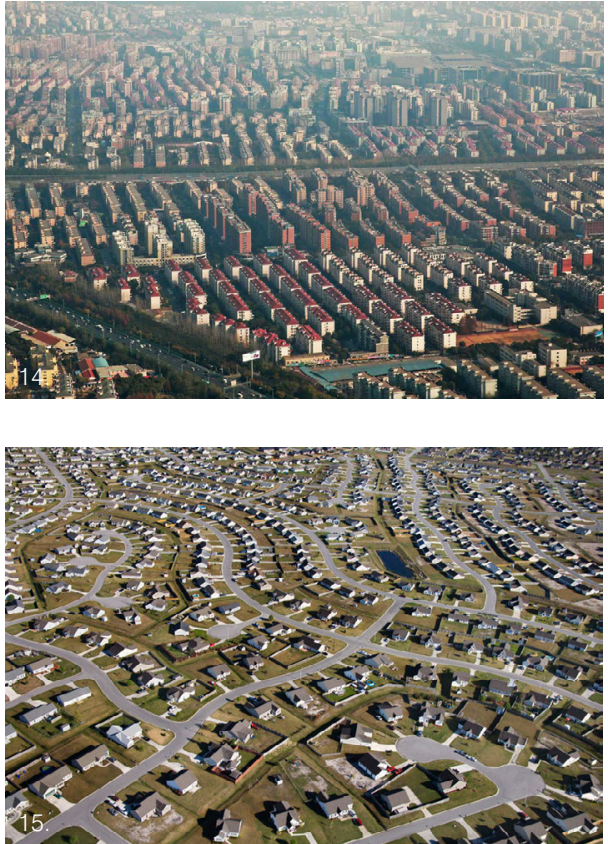

Though different in form and density, urban landscapes in China suffer from many of the same issues and challenges as low-density suburban developments in North America - most notably homogeneity and car dependence. 
tial enclaves encourage the formation of single-use, single-demographic communities $^{18}$ - a phenomenon associated with suburbs in North

\section{America.}

Market forces in the Reform Era have resulted in housing inequalities and a greater stratification of society. Several authors have noted similarities between residential developments in China and gated communities in the West. ${ }^{19,20,21,22}$ While gating and enclosure are longstanding features of Chinese urbanism, they are increasingly being deployed to segregate people of similar socioeconomic backgrounds and values.

\section{Expedient to a fault, superblock development in China has been suc-} cessful in accommodating immense urban growth in China in the last 30 years. Emerging issues, however, call into question its longer-term resilience and its appropriateness for the next 400 million rural-to-urban migrants. While current development practices have cultural significance, they must be reconsidered if these issues are to be addressed. notes

1. Duanfang Lu and Taylor \& Francis Group, Remaking Chinese Urban Form: Modernity, Scarcity, and Space, 19492005 (New York; London: Routledge, 2005): 141.

2. Youqin Huang, "Collectivism, Political Control, and Gating in Chinese Cities," Urban Geography 27, (6) (2006): 517

. Lu, Remaking Chinese Urban Form, 139

. Wang et. al., "Urban Infrastructure Financing in Reform-

5. Peter G. Rowe, East Asia Modern: Shaping the Contem porary City (London: Reaktion, 2005): 113

6. Huang, "Collectivism, Political Control, and Gating in

Chinese Cities".

7. Kjersti Monson, "String Block vs Superblock Patterns of Dispersal in China," Architectural Design 78, (1) (2008).

8. Lu, Remaking Chinese Urban Form.

9. Liang, "Planning and its Discontents".

10. Monson, "Sting Block vs. Superblock: Patterns of Dispersal in China".

11. Huang, "Collectivism, Political Control, and Gating in Chinese Cities", 518

12. Weiping Wu and Piper Gaubatz, The Chinese City

(Abingdon: Routledge, 2012): 270

13. Peter Calthorpe, "Weapons of Mass Urban Destruction, Foreign Policy, 09, Issue 195 (2012).

14. Axel Baeumler Ede lijasz-Vasquez Shomik Mehndiratta 14. Axel Bacu 09, Isue eds., Sustainable Eow Carbon Chy Development in China.

5. Bo Qin and Sunsheng Han, "Spatial Strategies for a Low Carbon Cly in China," in Transforming Chinese Cites, edited by Mark Y. Wang, Pookong Kee, and Jia Gao.

16. Pu Miao, "Deserted Streets in a Jammed Town: The Gated Community in Chinese Cities and its Solution,"

Journal of Urban Design 8, (1) (2003): 47.

17. Youqin Huang, "From Work-Unit Compounds to Gated Communities," in Restructuring the Chinese City, edited by Fulong Wu and Laurence J. C. Ma, (London: Routledge,

2005).

18. Fulong Wu, "Rediscovering the 'Gate' under Market Transition: From Work-Unit Compounds to Commodity Housing Enclaves," Housing Studies 20, (2) (2005): 241. 19. Rowe, East Asia Modern, 153.

20. Huang, "From work-unit compounds to gated communities"

21. Lu, Remaking Chinese Urban Form, 45.

22. Wu, "Rediscovering the 'Gate' under Market Transition". 


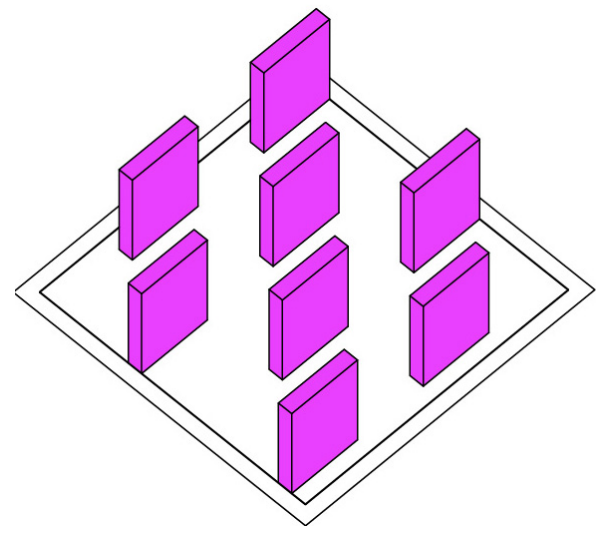

The simplified model above expresses the typical characteristics of urban development of Reform Era China. The model reflects typical density targets for residential developments. Repetitive single-unit-deep, 30-storey housing slabs are distributed across a 6.25-hectare parcel. Slabs face south to maximize solar exposure and are positioned to minimize the shadows they cast on each other.

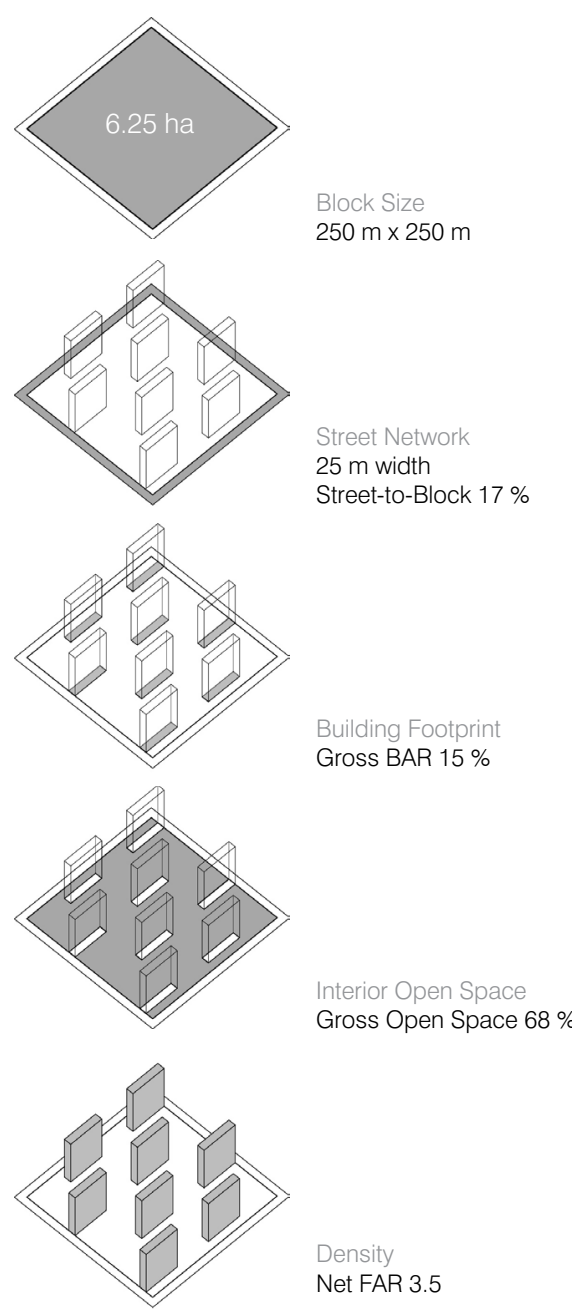

Standard Reform Era Superblock 
As noted in the previous chapter, the enclosure, gating, and repetition associated with the superblock - all of which stand in contrast to traditional Western street-oriented urbanism - have characterized Chinese urbanism for millennia. Historical urban forms that, like the superblock, followed a cellular pattern of development will now be analyzed in great er detail to explore how the spatial qualities of such development relate to a way of life unique to China. While certain practices persist into the Reform Era, the resulting environments differ significantly. An analysis of the ways in which current approaches to urban planning are consistent with or depart from longstanding practices may inform alternatives for future growth.

\section{Historical Cellular Urban Forms in China}

Traditional housing development in China has privileged the southfacing courtyard. Residential enclaves in northern Chinese cities were comprised of long, east-west bands of single-story courtyard houses separated by narrow laneways or hutongs. The traditional courtyard house or siheyuan was comprised of four connected buildings around a central courtyard. As such houses in these tight laneway neighbourhoods were internally focused and largely hidden behind the walls of the laneways. ${ }^{1}$ Just as individual houses were gated from the hutongs through which they were accessed, so too could hutongs be gated from the periodic wider, commercial streets that divided the city into larger
2 The Superblock as Indigenous Chinese Urban Form

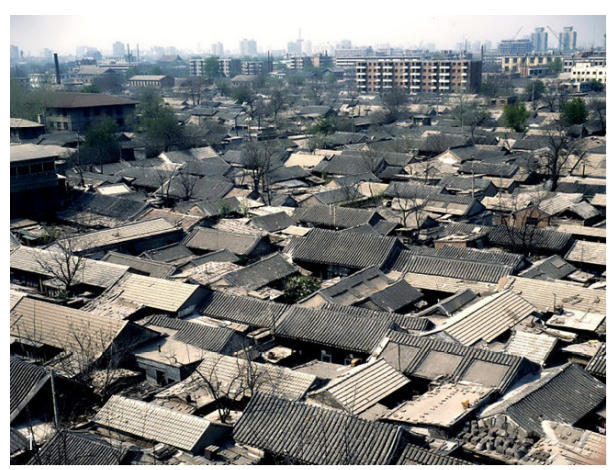

Hutong

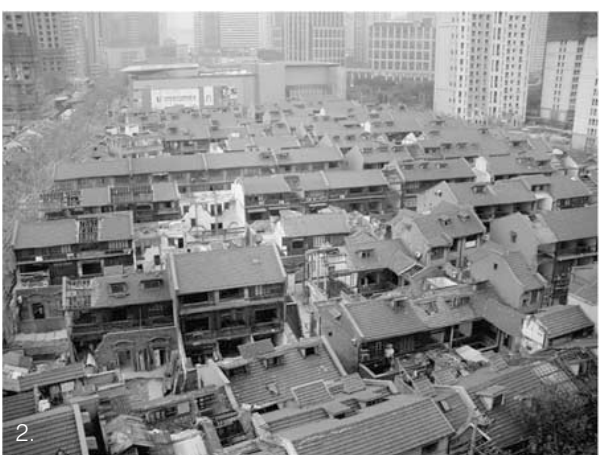

Lilong 
neighbuorhoods.

Courtyards acted as an ordering device for hutong neighbourhoods on both a formal and social level. Initially intended for a single family of multiple generations, courtyard houses were eventually divided into housing for multiple families. In both cases, the courtyard was "an essential commonplace for the immediate neighbourhood". ${ }^{2}$ As both an ordering device and a circulation space, courtyards fostered social interaction between residents.

Shanghai's lilong housing is a variation on the hutong. The term lilong (or longtang) refers to the parallel rows of housing separated by narrow east-west alleyways embedded within many of Shanghai's blocks. Notably, however, the characteristic housing type of these alleyway neighbourhoods differs from the siheyuan. Known as shikumen, the Shanghai laneway house is a hybrid between the traditional courtyard house and the European rowhouse. ${ }^{3}$

At the neighbourhood level, the lilong is quite cellular in nature. Organized into two- to five-hectare blocks, lilongs incorporate a hierarchical network of alleyways through which homes are accessed. Like the hutong, access to the interior of the block is limited to a few gated entry points along the larger, commercial streets surrounding the block. These points of entry lead to principal alleys that connect to the smaller lanes separating rows of dwelling units. Like Beijing's siheyuan houses, Shanghai's shikumen are all oriented south to maximize access to sunlight, resulting in a strikingly repetitive pattern of parallel east-west rows.
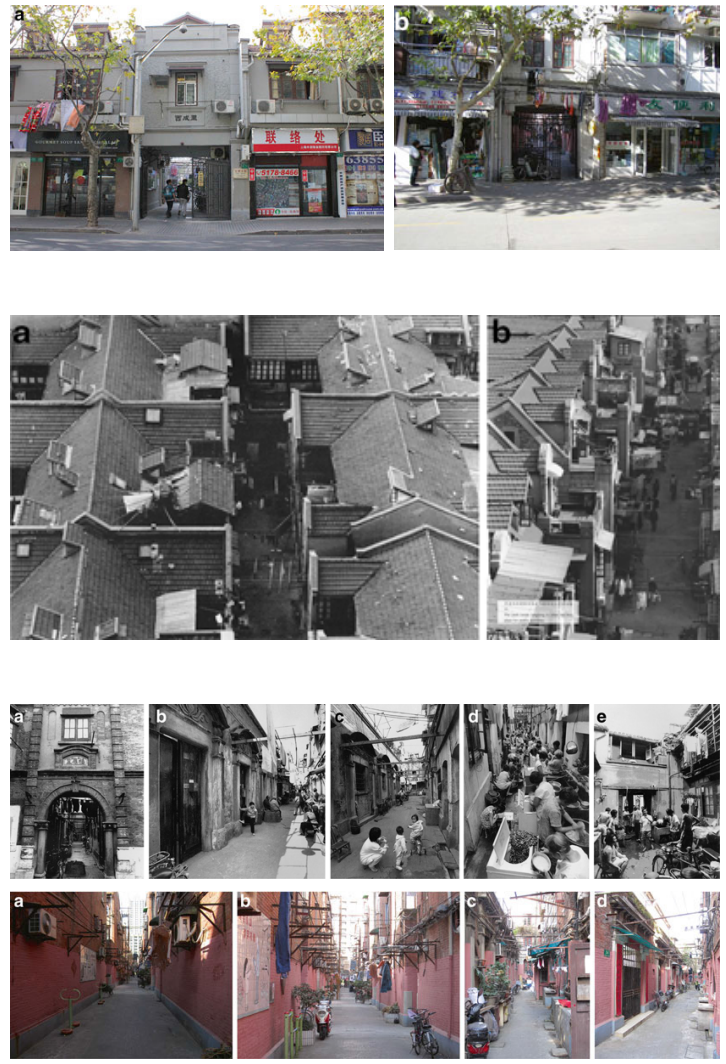

The lilong is accessible at a few gated entry points along the main commercial streets surrounding the block. These points of entry lead to principal alleys that connect to the smaller lanes separating the rows of dwelling units. The alleys are a communal space, used by the whole neighbourhood for various activities including storage, cooking, vending, socializing, and play

3.

Lilong 
Like the laneways of the hutong neighbourhoods, the main alley functions as a threshold space between the public realm outside the block and the private realm inside. It is used as a shared space by the whole neighbourhood for various activities including storage, cooking, vending, socializing, and play. Similarly, the narrower laneways between rows of housing are jointly used by the houses facing on to them. ${ }^{4}$

Concealed behind the walls of the compound, this protected network of laneways gives inhabitants a sense of ownership over their neighbourhood. The result is a kind of village within an urban block. Alleyways created a semi-private realm distinct from the public realm of the street. In this respect, the lilong contrasts sharply with the street-oriented urbanism of the traditional Western city where buildings - including individual residences - face onto public streets. By contrast, protected communal space is one of the key characteristics of traditional residential enclaves that has carried over the Reform Era superblock. The experience of the collective remains a central precept on which Chinese city planning is based.

Collective communal space also characterized the post-WWII danwei, or work unit. As part of the socialist planned economy instituted by the Communist Party in the 1950's, cities were divided into large walled compounds that functioned as self-sufficient communities. The cellular structure of cities in this era facilitated the centralized distribution of state welfare, managed primarily through the employer (typically a stateowned enterprise). ${ }^{5}$ Influenced by the Soviet planning concept of the

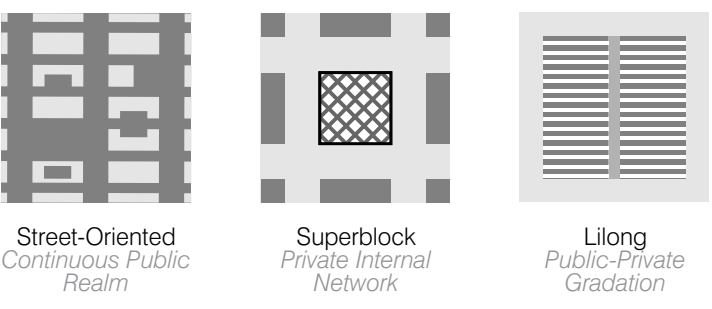

4. Street Network Comparison between Street-Oriented Development, the Chinese Superblock, and the Lilong
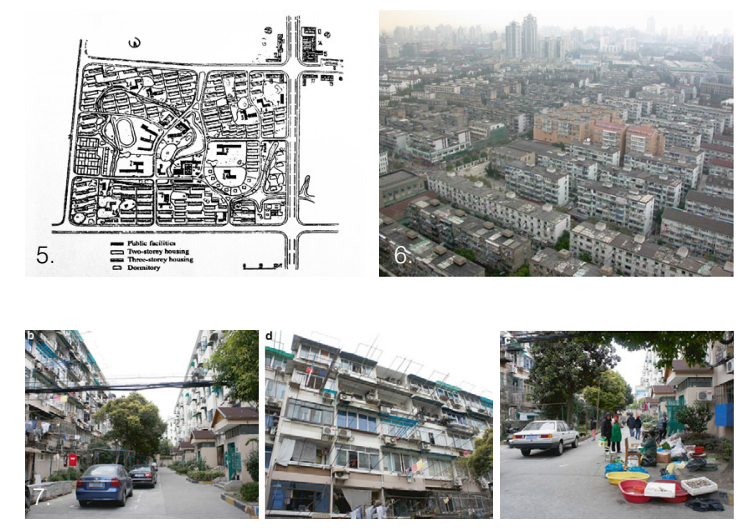

Danwei 
microdistrict, each danwei incorporated factories (or other enterprises), dwellings, schools and centralized services. ${ }^{6}$ Both the Soviet microdistrict and the Chinese work unit are, in turn, conceptually related to the Neighbourhood Unit proposed by Clarence Perry in the 1929 Regional Plan of New York. This concept will be discussed in greater detail in Chapter 3.

Incorporating all provisions necessary for daily life, individual danweis had little need to be integrated with the rest of the city, the whole of which was arguably equal only to the sum of its parts. Accordingly, these gated compounds were frequently separated from each other by wide roads. ${ }^{7,8}$ As with the hutong and lilong, open spaces within the danwe were communal, fostering a sense of ownership and community among the inhabitants. In the danwei, however, this sense of collectivity largely coalesced around the production of goods, as all residents worked for the same employer. This reinforced the vision of the classless society and of the greater good promoted under state socialism. The social compartmentalization of the work unit system is reflected in the autonomy and spatial separation of blocks.

Continuities and Divergences among Historical Urban Forms As evidenced by the hutong, lilong and danwei, a cellular pattern of urbanism has persisted across widely changing social and political contexts in China, as has the gating of communities and the provision of semi-private communal space. Expressions of the value placed on

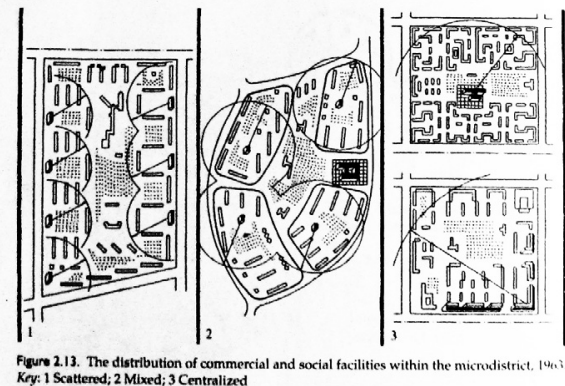

The microdistrict is a component of the Soviet planning system in which the city is hierarchically organized into neighbourhoods of decreasing size based on access to shared services.

8.

Microdistrict

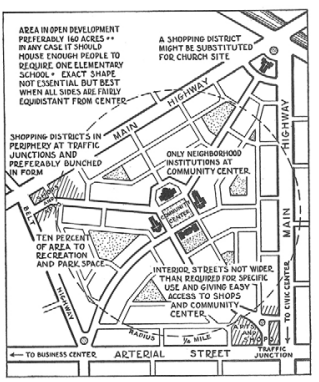

Perry's Neighbourhood Unit was intended as a prototypical module of cellular urban growth. With a population large enough to support an elementary school, each unit was to occupy approximately 160 acres so that servin in the centre could be accessed by all residents on foot. Shopping facilities, shared by adjacent neighbourhoots, were to belities, shared by adjacent neighbourhoods, reted units from each other. Roads internal to the unit wadesigned to discourage through-traffic

Neighbourhood Unit, Clarence Perry 
collectivity and security, these approaches to the subdivision of land could be described as fundamental to Chinese urban form. Arguably the placing of large parcels of land under the control of a factory or industry, as was done for the socialist era danwei, is the direct precursor to the practice of leasing large tracts of land to developers in the Reform Era. Indeed many of the socialist era property divisions have carried over.

Like the principle of enclosure, solar orientation, too, has endured as a key principle of Chinese urban form. Access to sunlight has played a significant role in the configuration of housing in the hutong, lilong and danwei. In each instance it manifests itself in a predilection for long, eastwest rows of south-facing housing. Not only is it unusual to find housing along north-south streets, but it's rare to find housing facing other housing across a street as it does in cities elsewhere. Typically the front of each row of housing faces the back of the adjacent row.

The height of buildings has increased over successive periods. Traditional siheyuan or courtyard housing were typically one story high, shikumen houses two to three stories, and danwei housing blocks averaged about six stories. With the increase in height came an increase in the space between rows of dwellings, largely to maintain an acceptable level of solar exposure for all units. This increasing "height-to-spacing" ratio has carried over into Reform Era developments, where south-facing high-rise slabs are organized into widely spaced rows.

However while general approaches to the organization of residential enclaves have remained consistent throughout time, it could be
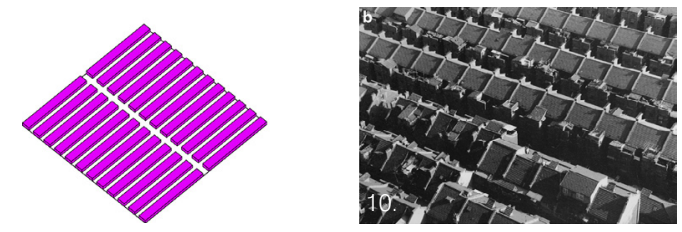

Lilong
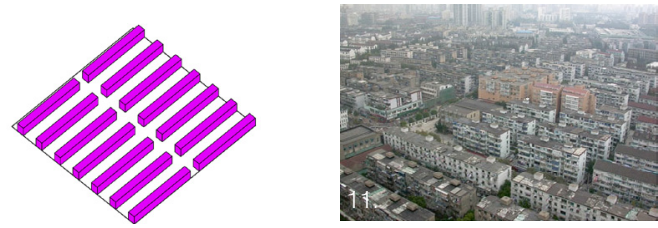

Danwei
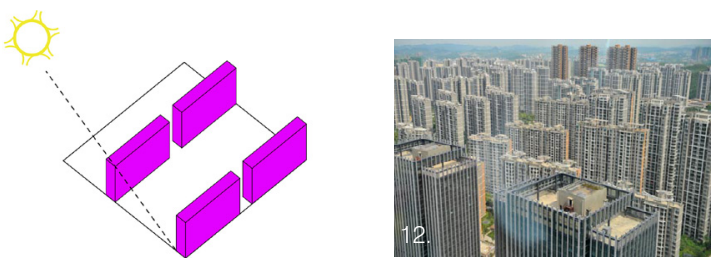

Superblock 
argued that key qualities and characteristics integral to the functioning of the hutong, lilong and danwei have been lost in the transition to Reform Era development. While an urbanism of independent cells embodied a social vision within the work unit system, for example, this vision has not carried over into Reform Era development. The sense of community associated with the danwei has diminished in the Reform Era, in which (for better or worse) the work and home lives of residents are much less integrated. Similarly we might argue that it's impossible to scale up the lilong, i.e., to swap tightly spaced rows of low-rise housing for widely spaced high-rise slabs, without significantly altering the way that neighbourhoods function. As tight laneways and individual houses give way to high-rise apartments separated by broad swaths of space, the nature of collective space changes - as does the nature of interaction it supports and engenders.

It could be argued that new times demand new spaces and that the inhabitants of modern tower ensembles are significantly different - in the way they relate to each other and to the state - than the residents of Treaty Port-era lilongs and socialist danweis. This still leaves open the question as to whether ensembles of repetitive towers are the most appropriate form for the new Chinese middle class or, indeed, whether this template should be applied to the 36 million units of social housing currently under construction in China. Transformed both by the heights of buildings and the scale of spaces between them, are Reform-Era housing ensembles still culturally relevant and resonant? To the extent
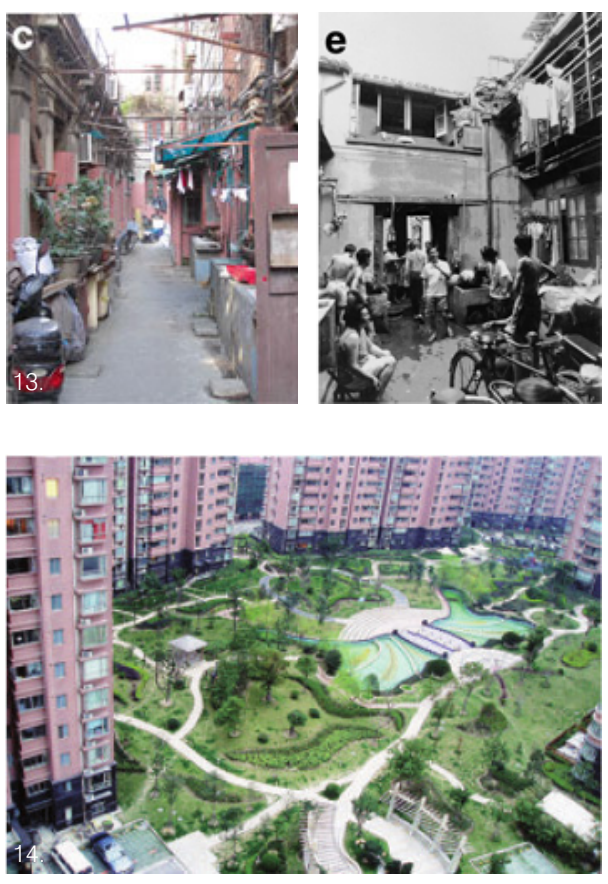

As tight laneways and individual houses give way to highrise apartments separated by broad swaths of space, the nature of the collective space changes as does the nature f interaction it supports and engenders. 
that market forces are "westernizing" the country, should approaches to urban planning in China become more Western? Will China's tower

complexes be subject to the same problems as were similar complexes in European and American cities? Or will social and cultural differences obviate this concern? Where changes are in order, should we be looking to the West or, to lower-scale indigenous models - or both? notes

1. Daniel Benjamin Abramson, "Haussmann and Le Corbusier in China: Land Control and the Design of Streets in Urban Redevelopment," Journal of Urban Design 13 (2) (2008): 235.

2. Wai Ki Pang, "Urban Morphology of Traditional

Chinese Cities in the Context of Modernization - A Case Study of Suzhou," 42nd ISOCARP Congress 2006: Cities between Integration and Disintegration (2006): 4.

3. Limin Hee, "Rethinking Shanghai's Urban Housing."

Urban Design International 12, (2-3) (2007).

4. Ibid.

5. Junxi Qian, "Deciphering the Prevalence of Neighborhood Enclosure amidst Post-1949 Chinese Cities: A Critical Synthesis," Journal of Planning Literature 29, (1) (2014): 6

6. Lu, Remaking Chinese Urban Form, 35-45.

7. Ibid., 51-67.

8. Abramson, "Haussmann and Le Corbusier in China". 
While cellular urban forms are indigenous to China, Chinese Reform Era superblock development bears undeniable formal similarities to postwar modernist housing complexes. Though they evolve from very different contexts, the Western superblock's ultimate effect on the city might provide insight into the longer-term resilience of superblock development in China. Further, the rethinking and retrofitting of superblock development in the West might inform adaptations to urban form in China to better accommodate future growth. Among the issues at play are the size and permeability of the superblock, the way it is built out (height, type, spacing and orientation of buildings), and the number of uses it is designed to support.

The Superblock in the West in the $20^{\text {th }}$ Century

\section{Vision}

As noted, the use of the superblock in the West is closely allied with the history of Modernism. The superblock as an urban form emerged in the West in the early $20^{\text {th }}$ century in response to the overcrowded $19^{\text {th }}$ century city. Poor living conditions coupled with a lack of space, light, and air plagued urban areas. In reaction, various planners proposed alternative visions for the city in which smaller blocks were amalgamated into larger ones to optimize the way space was used. These included both urban versions - frequently built-out with high-rises to free up more of the ground plane - and lower-scaled suburban versions.

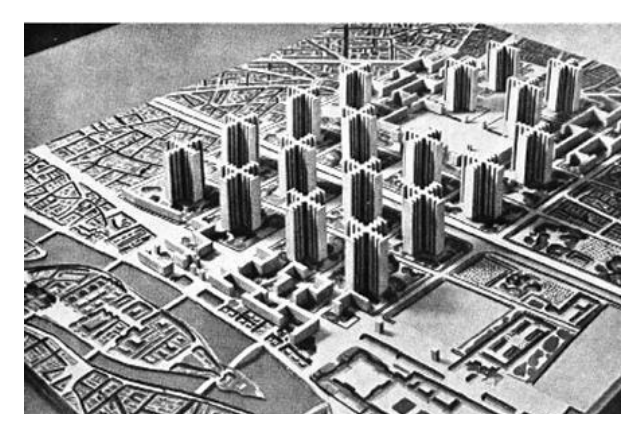

Le Corbusier advocated the use of tall buildings to open up space on the ground plane without sacrificing urban density. He proposed a rational organization of towers surrounded by open, park-like spaces - the "tower-inthe-park" prototype deployed for many high-profile urban redevelopment projects in the decades following World War II.

Plan Voisin, Le Corbusier, 1925

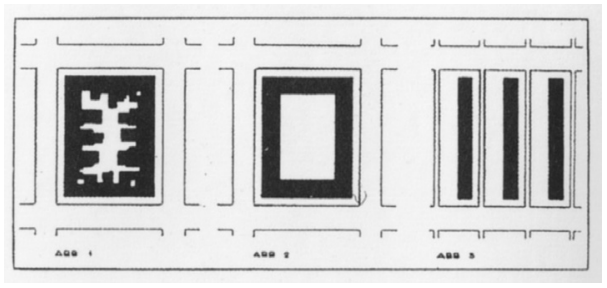

In the 1920's, Walter Gropius proposed to break up the overcrowded perimeter blocks of the 19th century into shallow bars to ensure access to space, light, and air.

2.

"From the Block to the Bar", Walter Gropius, 1925 
In the Ville Contemporaine, a proposal for a city for three million inhabitants, Le Corbusier advocated the use of tall buildings to open up space on the ground plane without sacrificing urban density. He proposed a rational organization of towers surrounded by open, park-like spaces - the "tower-in-the-park" prototype deployed for many highprofile urban redevelopment projects in the decades following WWII. Associated with this re-imagining of the physical form of the city was a vision for the lifestyle it would support. ${ }^{1}$ Functional separation was a basic principle. Reflected in the division of the city into residential, office and peripheral industrial districts, work-life and home-life of the middle class were envisioned as separate. Social reform through urban planning was to be implemented through a top-down system. Le Corbusier believed that a central authority must have ultimate responsibility for planning the city in order to ensure its efficient functioning. While reformers argued the advantages of implementing modernist planning at a large scale and on clear sites, its actual implementation in the West was frequently within the confines of the existing city.

In contrast to Le Corbusier's city of towers, low-scale variations on the superblock were proposed as alternatives to the problematic city in the early $20^{\text {th }}$ century. Clarence Perry's Neighbourhood Unit - mentioned above in relation to the danwei - was also a superblock, of sorts. Envisioned as a basic unit of urban development, its population was based on the number of residents required to support an elementary school. The school and other community functions were located in the centre of

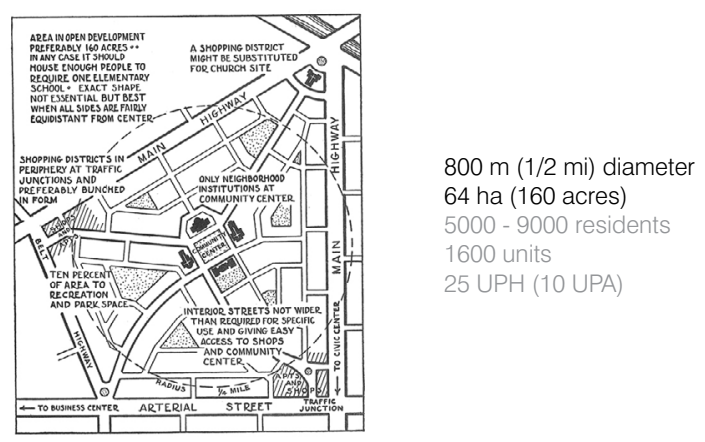


the neighbourhood to be easily accessible to all residents. At 160 acres (64 ha), Perry's neighbourhood was to be walkable. With a radius of just over $1 / 4$ mile $(.5 \mathrm{~km})$, residents were no more than a 5-minute walk from the services at the center of the community and businesses located along the perimeter. Bounded by thoroughfares, neighbourhoods were served by an internal network of curvilinear roads designed both to discourage through-traffic and slow the speed of vehicles to protect children and pedestrians. Like Corbusian planning, the neighbourhood unit was also based on functional separation. The interior of the block consisted exclusively of residences, open spaces, and community functions while commercial activity was pushed to the arterial roads around the perimeter, where is could be shared by adjacent neighbourhoods.

Based on the ideas of the Garden City attributed to Ebenezer Howard at the turn of the century, Clarence Stein and Henry Wright also proposed a hierarchical, modular system of urban development, best exemplified by their plan for Radburn, New Jersey. ${ }^{2}$ Like Clarence Perry, Stein and Wright promoted the neighbourhood as the building block of the city and correlated its size to the population necessary to support an elementary school. The neighbourhood was divided hierarchically into four tiers - the enclave, block, superblock, and neighbourhood. The scheme was served by a network of circulation routes that separated pedestrians from vehicles and residential from commercial functions. Major roads surrounded neighbourhoods while distributor roads surrounded superblocks, providing access to cul-de-sacs along which dwelling units

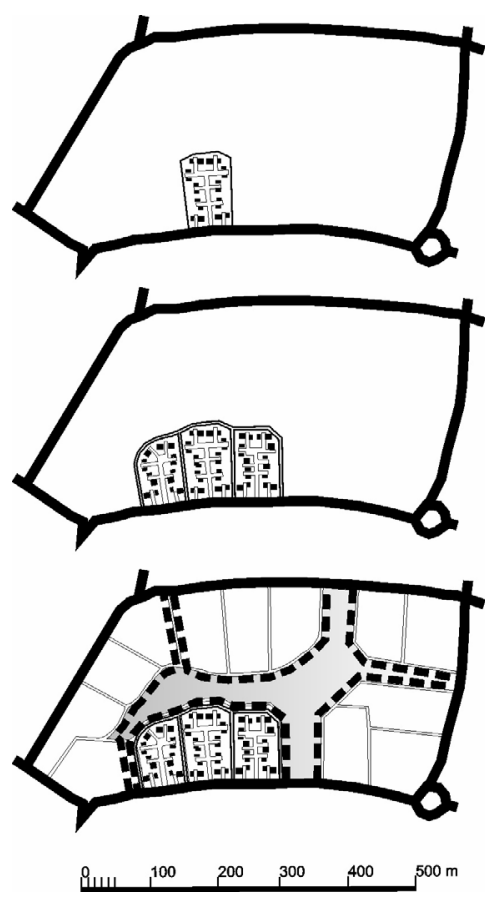

In their plan for Radburn, Clarence Stein and Henry Wright proposed a hierarchical module-based system for developing the city. Several enclaves of approximately 20 houses lining a cul-de-sac formed a block, each separated from each other with a pedestrian route used to access homes on foot. These blocks were in turn organized around a green space which formed what was termed a "superblock" by Stein and Wright. A neighbourhood was comprised of four to six superblocks. 
were located. Pedestrian paths and grade-separated crossings between enclaves enabled residents to reach the neighbourhood's central open spaces on foot without confronting vehicles. Individual neighbourhoods were to be aggregated into districts for the purpose of sharing largescale services. ${ }^{3}$

Influenced by these models, most post-WWII suburban subdivisions in the West are, in effect, superblocks. Like Reform-Era developments in China, they have limited entry and exit points, are frequently separated from adjacent subdivisions by arterial roads, are largely mono-functional (exclusively residential), and generally designed around the use of the car. Being subdivisions of agricultural land, suburban subdivisions are frequently quite large. That said, the post-war subdivisions of American cities are built out at low densities and with low-rise (predominantly single-family detached) housing.

\section{Reality}

In the face of the deterioration of the city and the popularity of lowdensity suburbs in the postwar era, modernist (i.e., "tower-in-the-park") superblock development in the West is most commonly associated with urban renewal. Sites deemed undesirable in the fabric of established cities were cleared and blocks were consolidated into superblocks. In Britain, the tower was deployed as a solution both to urban blight and for the large areas of cities that had suffered bomb damage in WWII. Abercrombie and Forshaw's 1943 County of London Plan was established to address housing shortages, in particular in the East End where slums

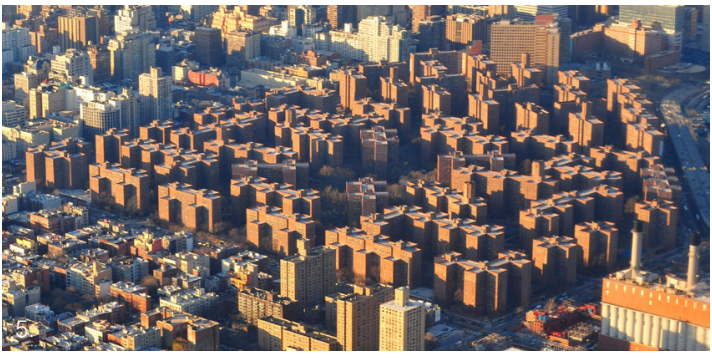

Stuyvesant Town in New York City is an example of an urban renewal project consisting of high-rise housing built by a private develope and made possible by state intervention. The form that resulted is large blocks of towers surrounded by open space, in stark contrast to the surrounding urban fabric.

Stuyvesant Town and Peter Cooper Village, New York, 1947 
had already been identified as a problem prior to WWII . ${ }^{4}$ The Plan set minimum densities for new development to ensure adequate housing. This presented the opportunity for towers to be introduced into the city as a means to meet the density targets.

In the United States, slum clearance was institutionalized by the Housing Acts of 1949 and $1954 .{ }^{5}$ Federal funding was offered for the clearance of blighted urban areas in order to provide both middle class and lower class housing. The Act gave municipal governments the power to designate, purchase and demolish slums and subsidize the land for purchase by private developers. The result was comparatively large blocks of towers surrounded by open space, as exemplified by the many housing projects in New York City spearheaded by Robert Moses. Like Chinese Reform Era urban development, urban renewal projects were influenced by both public and private entities.

Critiques

Urban, "tower-in-park" redevelopment projects were heavily criticized for creating isolated enclaves that broke up the existing urban fabric. Jane Jacobs harshly regarded them as the antithesis to what a successful urban centre should be. ${ }^{6}$ Where she believed mixed functions were the key to having many people inhabiting spaces at different times of the day, the superblock was mono-functional. Moreover, the large open spaces of the superblock were often empty and dangerous. At four to twelve times the size of a traditional urban block, the absence of through streets - intended to create extended safe spaces for children

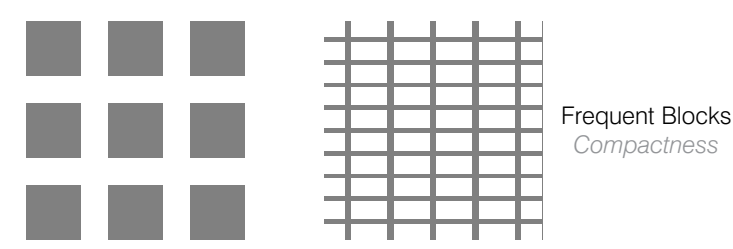

1 1 1 1 10 Mixed Functions Diversity

6 Conditions for Successful Cities according to Jane Jacobs 
to play - was criticized for reducing pedestrian access and making the city more difficult to navigate. Finally, given the terms of reference under which they were realized and the fact that large tracts of urban land were built out by the same agency at the same time, urban renewal projects did not consist of the mix of buildings that Jacobs believed were vital to a well functioning city. With a large area under the control of a single developer, these projects produced repetitive, homogeneous environments.

Superblock "tower-in-the-park" planning failed most spectacularly when it was used for social housing - which was the case for many slum clearance projects. The problems are exemplified by the failure of Pruitt-Igoe in St. Louis. The public housing complex was designed on a cleared site whose previous housing was in poor condition. Though initially considered successful, the towers soon suffered from high vacancy rates. When the project was forcibly desegregated, socially mobile families decamped to the expanding suburbs leaving only the poorest and most disenfranchised of residents. The rents of these lowincome tenants were insufficient to cover maintenance costs. Common areas, such as corridors, stairwells and the large expanses of land at the base of the towers were particularly vulnerable to decay. The failure of public housing complexes like Pruitt-Igoe demonstrates the challenges of accommodating low-income families in enclaves of high rises. While the architectural and urban vision was only one of many problems, the modernist superblock arguably exacerbated many of the social issues it
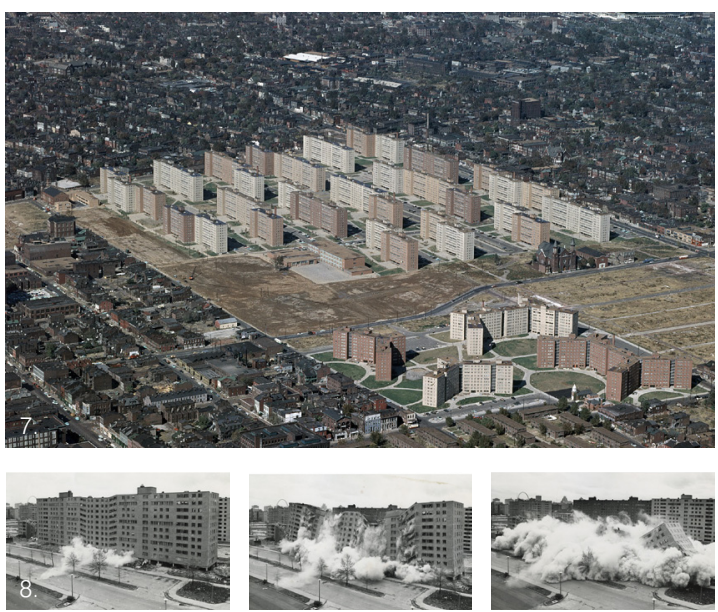

Pruitt-Igoe, St-Louis, 1954 demolished 1972 
set out to address.

Comparison and Contrast of Western and Chinese Superblock Planning

In both China and the West the use of superblocks in urban areas is associated with top-down planning and what Jane Jacobs characterized as "cataclysmic" funding. Thus, the Chinese superblock in many ways resembles its Western counterpart, possessing many of the characteristics that made the Western superblock so vulnerable to criticism. But however modernist it might appear, as suggested, the roots of the Chinese superblock lie elsewhere. Its emergence and function are inseparable from the specific spatial, historical, and cultural context of Chinese cities.

The following section will attempt an analysis of the similarities and differences between Western and Chinese superblock development to better assess the ultimate appropriateness, resilience, and sustainability of the approach for its context. Such analysis will also allow the Western experience with the superblock to inform future development in China

\section{Similarities}

Superblocks in the West (as exemplified by urban renewal projects) and those in China are both characterized by homogeneity and repetition. This reflects the rapid pace and scale at which they are realized. Superblock development in China is facilitated by the state. The great influence the state has based on its ownership of all land in the country allows for such large-scale subdivisions of land to be possible. Such

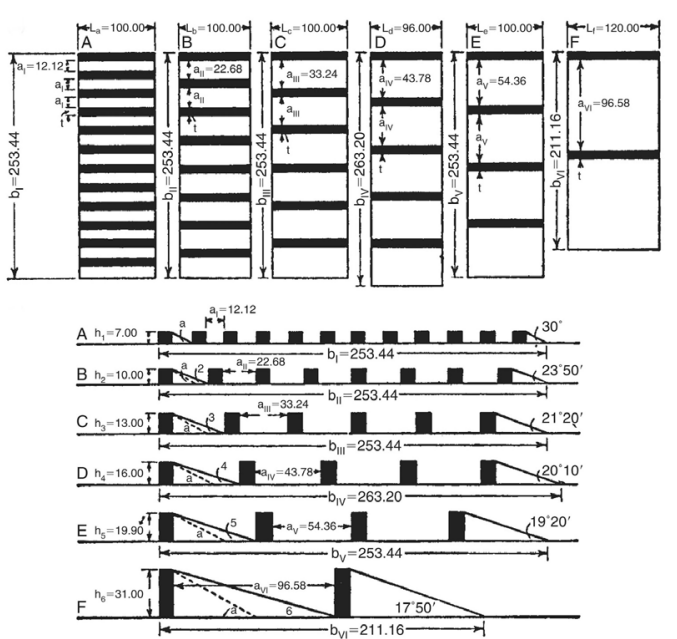
Concept for spacing of residential slabs, Walter Gropius, 1929

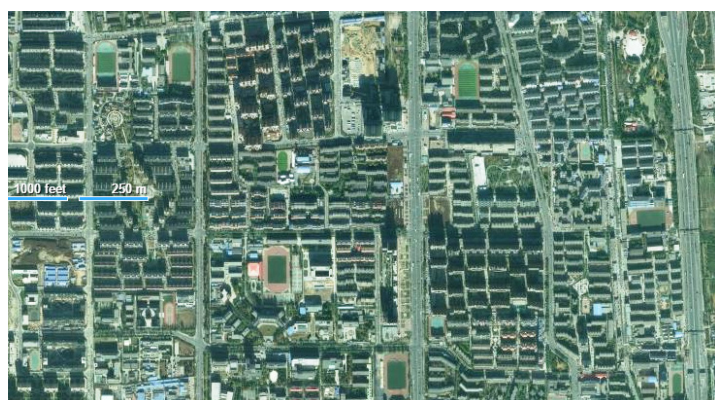

10.

Aerial view of suburb to the south of Beijing

Modernists like Walter Gropius promoted the idea of spacing residential slabs to maximize access to light and air. With regulations for minimum solar exposure, similarly shallow, repetitive rows are ubiquitous in urban areas in China. 
development is favoured by a powerful central authority, which acts as the ultimate planner. ${ }^{7}$ This strategy is also associated with modernist

planning where large swaths of irregular, fine-grained fabric were cleared to make way for more rational and efficient large-scale divisions. Superblocks in the U.S. resulted from political power granted to municipal governments by the Housing Act to expropriate and clear large areas of the city for urban renewal. Subsequently subsidized for purchase, these projects were private developments made possible by state intervention. The land leasing system in China creates a similar dynamic between the state and the market, influencing the formation of large-scale urban divisions, the build-out of which is controlled by developers.

Both Perry's neighbourhood unit and the gated Chinese superblock favour a semi-private realm within the block, the design of which discourages non-residents from entering. In both cases an internal network of roads functions independently of the public thoroughfares that surround and separate blocks. Both the Modernists and proponents of neighbourhood planning in the West advocated a separation of modes of transportation. This was accomplished through a hierarchical system of circulation routes designed for different modes and speeds of travel as compared to an all-purpose grid of streets shared by both pedestrians and vehicles. This hierarchy of space and streets as well as the separation of functions is common to both Western ideas for the superblock and Chinese residential development in the Reform Era. 


\section{Differences}

Urban growth in China, in general, is inherently tied to its political context. Large-scale development is facilitated by a top-down government, which has the political power to implement cellular urbanism throughout the entire city and provide infrastructure at the scale of the large blocks. While superblocks in both contexts are private-led development made possible by large-scale state intervention, their location within the city generally differs. Superblock development in the West largely occurred in decaying areas of established city centres, where smaller, pre-existing blocks were consolidated. Envisioned as oases of green in an otherwise dreary core, these urban renewal projects stood in stark contrast to the surrounding urban fabric. In Chinese cities, much of superblock development is occurring on previously undeveloped land on urban fringes along with appropriately large infrastructure. Commensurate with Le Corbusier's exhortation to build on clear sites, these "suburban" Chinese superblocks create the urban context rather than departing from it. The traditionally dominant form of urbanism in the West, the grid of small-scale plots and parcels, encourages private ownership and development at the scale of the individual. This reflects Western values of individual land and property rights as opposed to the collective scale of development in China where such values are weaker. Where the introduction of the superblock into the Western city represented a departure from the finer-grained urbanism that dominated the urban landscape, cellular development in China has long been the default

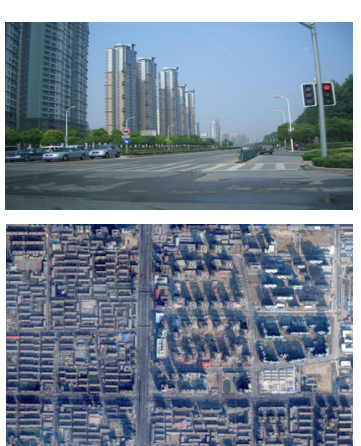

Beijing

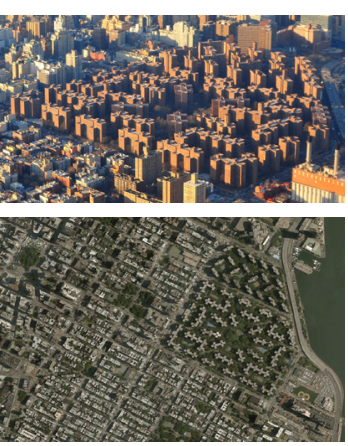

Manhattan

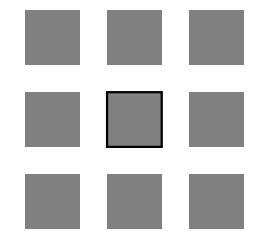

Chinese Superblock

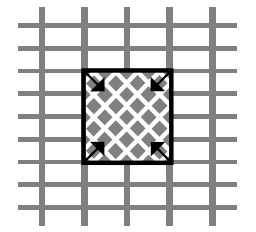

Western Superblock 
means of planning cities.

While Jane Jacobs and others criticized the use of large-scale superblocks in urban centers, they continue to form the basis for suburban development in the West. In terms of its location, superblock development in China can be considered suburban inasmuch as it is used principally for the build-out of the urban periphery. The form that this development takes, however, resembles urban fabric in the West.

In China, dense high-rise development characterizes cities and suburbs alike. Though modernist urban renewal projects were frequently at odds with the urban fabric into which they were introduced, their density was consistent with the neighbourhood. Proposals like the Neighbourhood Unit and Stein \& Wright's model consisted of low-scale development outside cities. Thus high-rise superblock development on urban peripheries in China diverges from these Western approaches. From a Western perspective, the Chinese superblock is a hybrid of both urban and suburban forms.

Both occurrences of the superblock appear pragmatic and rational, containing a similar pattern of repetitive rows of high-rise towers. However the similarity of the forms belies the respective times and circumstances under which they were built. While the tower-in-the-park typology was deployed in response to the decaying core of the North American city of mid $20^{\text {th }}$ century, the superblock in China responded to the massive rates of urbanization in Reform Era China's cities. Pragmatic methods of construction were valued for their expediency in develop- 
ing the city in the face of this urbanization as well as in light of the profit motives of private developers. Developing the city in cellular blocks served as a means developing the city quickly and generating revenues for local governments. This dynamic behind urban development in the Reform Era added up to an urban form that resembles the modernist tower-in-the-park landscape, but contrasts with the ideological vision of the Modernists that underscores superblock planning in the West.

Unlike the pragmatically-developed towers of the Western superblock, which reflect a desire for order in the face of a chaotic urban landscape, the repetitive, row-like configuration of towers in the contemporary Chinese superblock reflect a longstanding and culturally ingrained concern for solar exposure. The continuities that exist from traditional urban form in China into the superblock represent underlying intentions that differ from the desire of the Modernists to find a completely different way of planning cities in the West. Building high to open up space around buildings represents a reactionary alternative to what were seen as cramped cities devoid of light and air at the turn of the century rather than the expression of a longstanding preoccupation with the solar orientation of housing. Open spaces in Chinese superblock development can be interpreted as a semi-private realm which establishes privacy and security for residents, a concept that has been inherent to Chinese urban form throughout history. This concept does not apply to Western cities where streets and the occasional public park form a common public realm and where the remaining space is divided up into private yards.

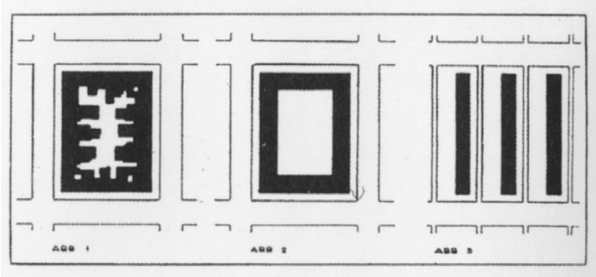

"From the Block to the Bar", Walter Gropius, 1925

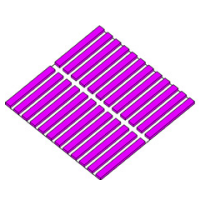

Lilong

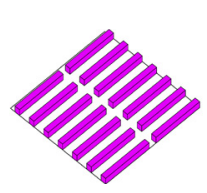

Danwei

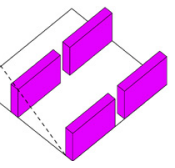

Superblock Influence of Solar Exposure on Urban Form

Unlike the pragmatically-developed towers of the Western superblock, which reflect a desire for order in the face of a chaotic urban landscape, the repetitive, row-like configuration of towers in he contemporary Chinese superblock reflect a longstenting in culturally ingrained concern for solar exposure. 
Representing a divergence from the past, the creation of the semi-private open space within residential compounds in the West is a result of the idea of functional separation for the more efficient functioning of the city as a whole. The enclosed spaces within Chinese superblock development, on the other hand, are inherited from the danwei and serve a similar function as the lanes of the hutong and lilong.

Both the Chinese and Western superblocks emerged in times of great change. The massive urbanization of Reform Era China starkly contrasts with the massive exodus out of city centres that occurred in North American and later, European cities in the mid $20^{\text {th }}$ century. Expanding suburbs and the opportunity to own property proved to be a more appealing choice for the middle class who could afford to leave the decaying city. While the lure of suburbs resulted in many Western superblocks becoming the exclusive domain of low-income households, virtually all demographic groups in China are directed to towers. The scarcity of land combined with the population of cities make dense, high-rise living an inevitability in China for all classes of urban dwellers. This diversity contrasts the eventual class segregation, which led to the ultimate failure of the Western superblock.

Different Contexts, Similar Issues

While the superblock did not meet its original intentions in the West and was largely abandoned as an approach, the superblock remains the default method of urban development in Reform Era China. The lack of other choices for the urban population has created a forced diversity 
in superblock developments leading to the type's greater sustainability compared to its Western counterpart - at least in the short term. Urban housing in China, however, is beginning to experience social and environmental problems. The increasing influence of the market in shaping cities in the Reform Era has created more choices for the Chinese population and more opportunity for social segregation. ${ }^{8}$

It is clear that large-scale, enclosed superblock development, a variation of which has been prevalent in China throughout history, is more appropriate for the Chinese context than it has proved to be in the West. However, the problems which are emerging in Chinese cities that have plagued cities elsewhere are being exacerbated by cellular development in its current form and thus it may not be the best approach in the long term. Thus, China may be able to look to Western solutions to similar urban problems in adapting its urban form for future growth. notes

1. Peter Hall, Cities of Tomorrow: An Intellectual Histon of Urban Planning and Design in the Twentieth Century Oxford: Blackwell Publishers, 2002): 22

2. Nicholas Patricios, "Urban Design Principles of the Original Neighborhood Concepts" Urban Morphology 6.1 (2002): 4

3. Ibid., 6.

4. Hall, Cities of Tomorrow, 235

5. Ibid., 248

6. Jane Jacobs, The Death and Life of Great American Cities (New York: Random House 1961).

7. Abramson, "Haussman and Le Corbusier in China",

8. Huang, "From work-unit compounds to gated communities". 
Reaction to Superblock Development in the West: New Urbanism

The experience with the modernist tower-in-the-park and the proliferation of the suburb in the $20^{\text {th }}$ century spurred a reactionary movement in the West to re-evaluate the characteristics for "good" urban form. In the vein of the recommendations of Jane Jacobs, New Urbanism emerged as a movement to return to principles of traditional urbanism. First codified into the Charter of the New Urbanism in the early 1990s, these principles have since been incorporated into the LEED for Neighbourhood Development standards. Its principles, as described in the LEED standards, encourage a pattern of urbanism for future growth that will be more environmentally sustainable than the "predominant development pattern of the last 50 years". ${ }^{1}$ Advocated is compact, mixed-use neighbourhood development to achieve walkable environments and, in turn, to reduce dependence on the automobile. Mixed-use developments are promoted so that jobs and residences are in close proximity to each other. Small, frequent blocks are favoured to reduce the speed of traffic in order to cater to the pedestrian and encourage a diversity of buildings at a walkable distance from one another. Transit-oriented development is encouraged through establishing minimum proximity of new developments to transit stations. The social functioning of the city is another goal of sustainable urban planning according the LEED guide. It suggests that an optimal neighbourhood should include housing of various types and price
4 Universal Solutions vs. Cultural Specificity

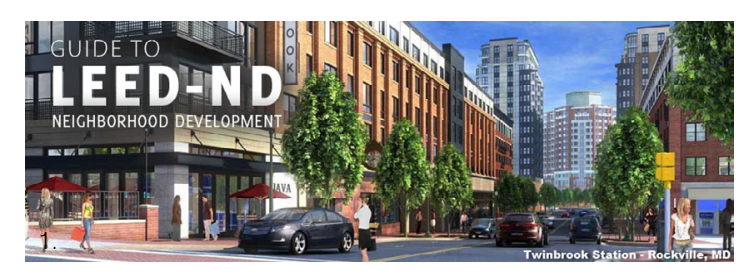

LEED for Neighbourhood Development standards encourage compact, mixed-use neighbourhood development to achieve walkable environments and, in turn, to reduce dependence on the automobile. 

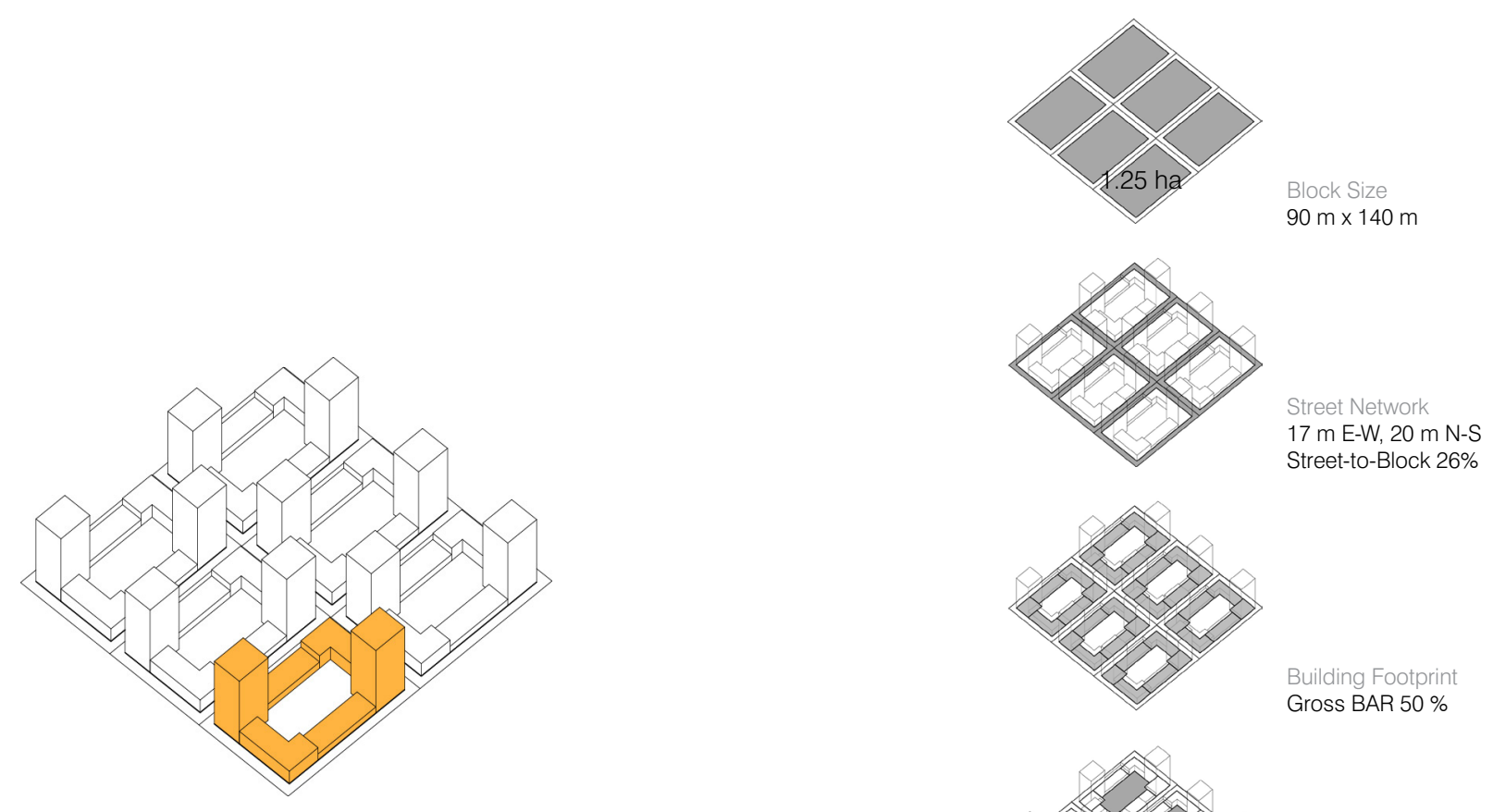

temonstrates how principles of New Urbanism may be applied to the build-out of an urban block. Lining the perimeter of the block, residential buildings are entered from and engage the street.

The block size is determined by the maximums proposed in LEED-ND for walkable neighborhood development; the block is proportioned so that the longest side of the block is $140 \mathrm{~m}$ and the total block perimeter comes to $460 \mathrm{~m}$. The long sides of blocks form secondary streets while the short ends face onto wider, primary streets. The block incorporates three building types, providing a diversity of housing sizes and options for a range of demographic groups. High-rise towers (30-storeys) are positioned at opposite corners to maximize the distance between them Mid-rise buildings (6 storeys) facing primary streets accommodate commercial usages at grade. Lined with

row houses, secondary streets, are lower in scale and more residential in character.
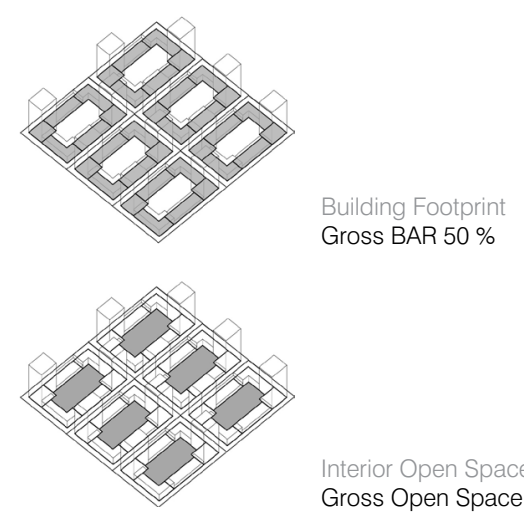

Gross BAR $50 \%$

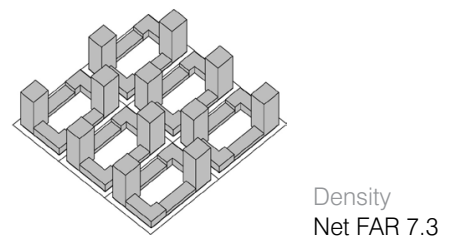


ranges to "enable a wide variety of residents to be part of the community". ${ }^{2}$ Human-scaled buildings and streetscapes are recommended to encourage walking and create an "inviting public realm" which includes places shared by the community "where the public feels welcome and encouraged to congregate". ${ }^{3}$

The genre of urban development sanctioned by New Urbanists has been commonly accepted in the West as ideal urban form, with principles of street-oriented urbanism being incorporated into planning guidelines of many cities. ${ }^{4}$ Buildings are expected to engage the street and actively foster a public realm at grade for pedestrians. For towers, this often translates into residential units which sit on a pedestal in which commercial space is housed and that is directly accessible from the street. This type of development pattern is associated with "Vancouverism". Such high density, high-rise communities fulfill the goals outlined by New Urbanists by creating a pedestrian-scaled realm with a diverse mix of uses within walkable proximity of each other.

\section{New Urbanism as an Alternative to Chinese Superblock}

\section{Planning}

In schemes for several urban centres in China, Peter Calthorpe has attempted to address the issues of current practices of urban development by applying the principles of New Urbanism. To address the increasingly car-centric and segregated Chinese city of superblocks, he has proposed to introduce a new pattern of development with the aim
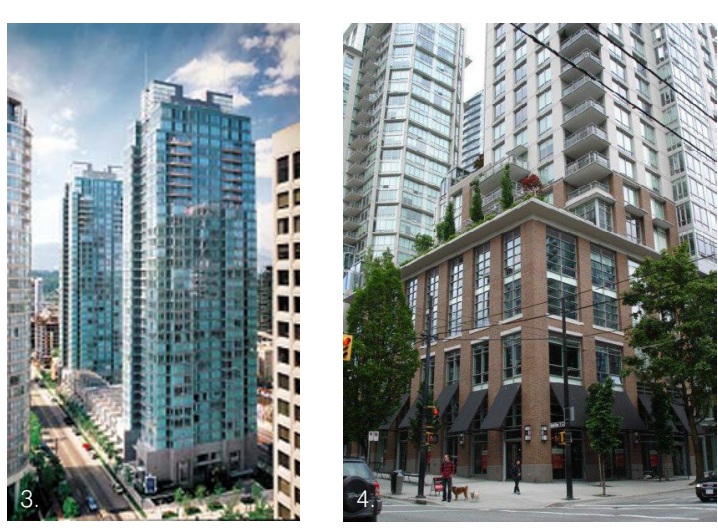

The genre of urban development sanctioned by New Urbanists has been commonly accepted in the West as ideal urban form. Buildings are expected to engage the street and actively foster a public realm at grade for pedestrians. These principles are associated with a development pattern known as "Vancouverism" — residential towers sitting on a pedestal in which commercial space is housed and that is directly accessible from the street. 
of producing a more human-scaled, pedestrian-oriented environment. As an alternative to cellular urbanism, this would approximate an urban form characteristic of traditional Western cities, which is oriented around the street as the centre of urban life. Seeing China's urban problems as evidence that it is making similar mistakes as the West, Calthorpe proposes Western-derived solutions to counter the issues at play. ${ }^{5}$

Calthorpe's proposals are based on the key concepts of diversity and walkability, which are seen by New Urbanists as inherent to the street-oriented development of traditional urban centres in the West. The mixed-use development and pedestrian-scale streets that they advocate differ from the single-use, single-demographic enclaves separated by wide arterial roads characteristic of cellular development in China. Calthorpe proposes the introduction of a finer grain of urban fabric of smaller blocks and narrower streets than those associated with current superblock planning in China. The street network is designed to cater more to the scale of the pedestrian by maintaining a smaller width and a more varied streetscape. Integrated with this is a network of open spaces of parks and plazas in which civic functions are located designed to provide easy access to people on foot and bicycle. ${ }^{6} \mathrm{~A}$ continuous public realm is formed as opposed to a series of enclosed open spaces A diverse range of functions is encouraged through the distribution of mixed-use zones throughout the city.

To reduce car dependence, Calthorpe's proposals emphasize the integrated planning of transit systems with the rest of the city - some-

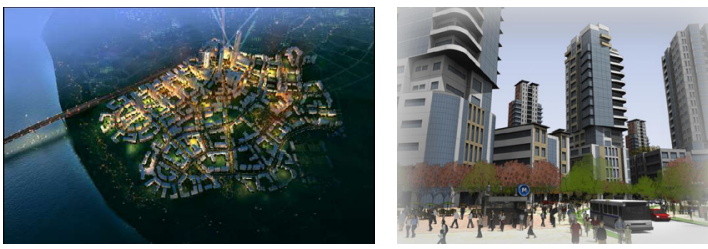

Yuelai Eco-City, Chongqing, Calthorpe Associates
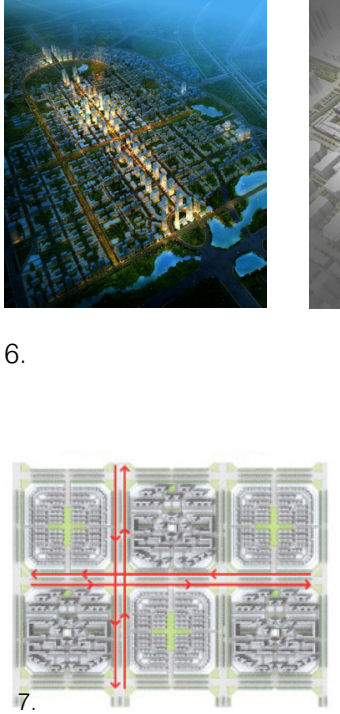

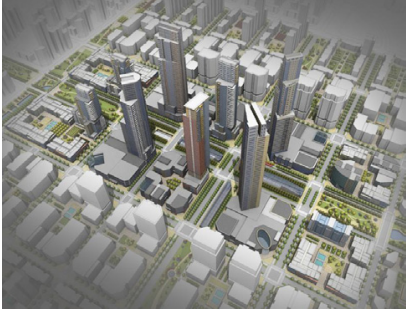

Chengong New Town, Calthorpe Associates

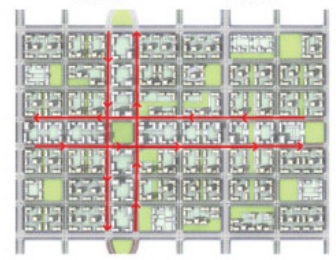


thing that China has done remarkably well. Pockets of higher density development surround transit stations in order to maximize the potential for transit use. The mono-functionality of exclusively residential enclaves combined with the wide streets which separate these blocks in Chinese cellular development impede the walkability of Chinese cities, leading to an increased car use. Further, smaller lots of diverse uses and housing types offer a distinct alternative to the vast, homogeneous blocks of repeated building types that is currently the norm in China. It also introduces the possibility of social mixing (different demographic groups occupying different types of housing in the same compound). The possibility for different types of buildings and developments in closer proximity to each other encourages the appearance of communities with a more diverse cross section of residents.

The Future of the Superblock: Towards an Adapted Approach to Urban Planning in China

Chinese urban form in the Reform Era possesses characteristics that both relate it to and distinguish it from cities elsewhere in the world. The adoption of certain Western values in China as it has modernized has led to the emergence of similar problems as in the West. It may be reasonable, then, to incorporate Western solutions to address these problems. The principles of walkability and diversity that characterize Calthorpe's approach undoubtedly have potential to address the issues afflicting current urban development in China. These principles, like the
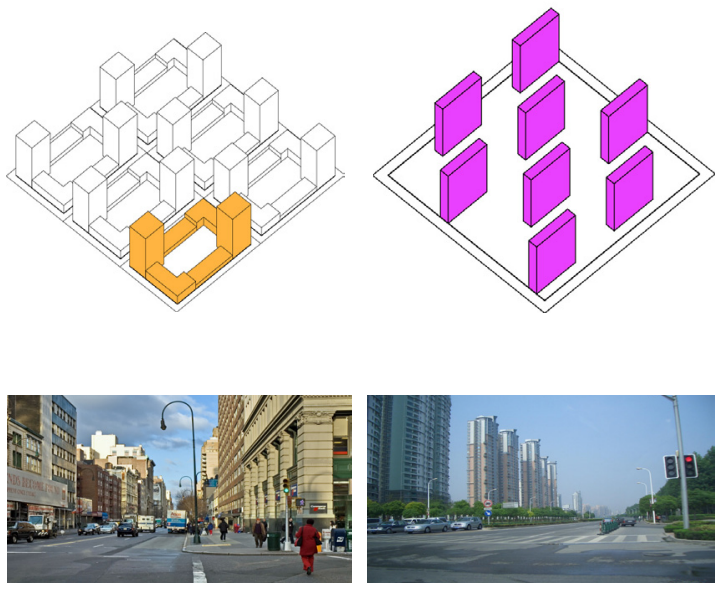

The differing urban environments produced from the street-oriented development advocated by New Urbanists and Chinese superblock planning 
large-parcel, "tower-in-the-park" planning to which they are intended to be an antidote, however, represent a one-size-fits-all approach to urbanism. While in the West, New Urbanism represents a return to traditional urban principles in the face of problematic urban landscapes associated with the $20^{\text {th }}$ century, such principles are foreign to China where cellular urbanism is indigenous. It is assumed that this model will produce better, more liveable, and more sustainable communities wherever they might be located. However, as discussed, these principles have been conceived specifically as a response to problems with development patterns in a Western context, such as tower-in-the-park urban renewal projects and suburban sprawl. Used as "universal" solutions in China,

Western approaches largely ignore (or misinterpret) the unique cultural, geographical, and demographic peculiarities of its urban form. A complete overhaul of the superblock pattern of development as proposed by Calthorpe dismisses its cultural relevance, ignoring the fundamental principles that have persisted in Chinese urban form throughout time.

Instead of seeking an alternative, an adaptation of current approaches to the build-out of cities could result in a more culturally specific approach to building out Chinese cities in the future. The proposal in the following chapter will seek to establish a hybrid of universal and culturally specific elements as a means of accommodating future urban growth.

Understanding that large-scale enclosed urban blocks may still prove appropriate and resilient for future growth in China the question become 
less one of what is done than of how it is done; less about the superblock than how it is built out. A closer consideration of Chinese and

Western cellular urban patterns may provide insight into how to adapt the superblock to better respond to the needs of Chinese cities.

Superblock development in China has been remarkably effective and efficient in accommodating urban growth. Development in large parcels, as opposed to small lots, is not only practical but necessary when accommodating the unprecedented population growth occurring in Chinese cities. As such, it will likely continue to be deployed. Furthermore, as noted, superblock development is consistent with cultural values of security and collectivism in China where housing has long been separated in gated enclaves. It can be argued that the perception of security afforded by such development is de rigeur in China and that New Urbanist approaches are inappropriate and inapplicable inasmuch as they dismiss gated enclaves in favour of street-oriented urbanism. Maintaining the collective as a basis for urban development may produce a more culturally relevant solution.

As noted, issues with superblock planning arose due to the commodification of housing in the Reform Era where urban form, in contrast to the danwei of the communist era, is largely determined by the developer resulting in single-use, single-demographic environments. Prior to reform, Chinese cities were characterized by gating and enclosure yet did not suffer these same issues. In the transition to the widely spaced towers of the Reform Era, integral aspects to the functioning of histori-

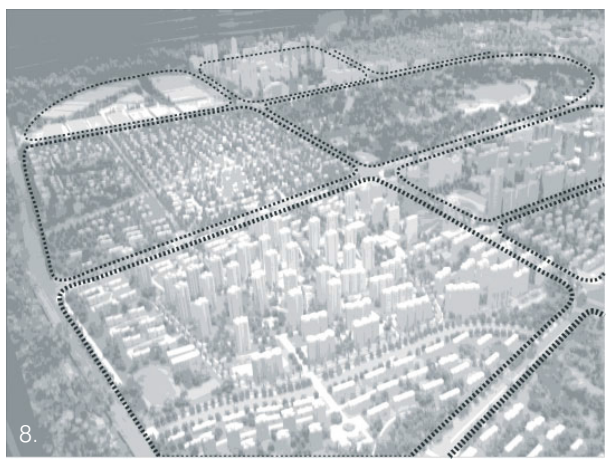


cal forms have been lost. If it is to continue to take on a cellular pattern, an adapted urban form could reincorporate certain aspects of historical forms to address the problems of current development.

Historical forms functioned on a social level within a cellular scheme. The hutong and lilong fostered a sense of community through the establishment of a semi-private realm. With its hierarchy of spaces creating a gradual threshold between public and private space, each cell provided a sense of being part of the larger group of its residents. In the Reform Era, this transition has become extremely abrupt and each block consists of a much higher population. This concept of gradation of space could be reintroduced in the Reform Era by breaking down this population into smaller collectives, reintroducing social cohesion into the city.

As part of a system of integrated planning, the danwei ensured that all aspects of daily life were accommodated. Designed to facilitate the provision of amenities and services to the population, the frequency of these services was determined by the amount of people included in each work unit. The compartmentalization of the population in socially and economically defined collectives ensures that sufficient urban amenities are provided. With such rapid and widespread urbanization occurring in China, cellular growth could be practical for ensuring that services are provided to the incoming population at an appropriate scale. While a school is currently provided to a residential enclave by the municipality, other services are lacking, leading to the necessity for trips further away
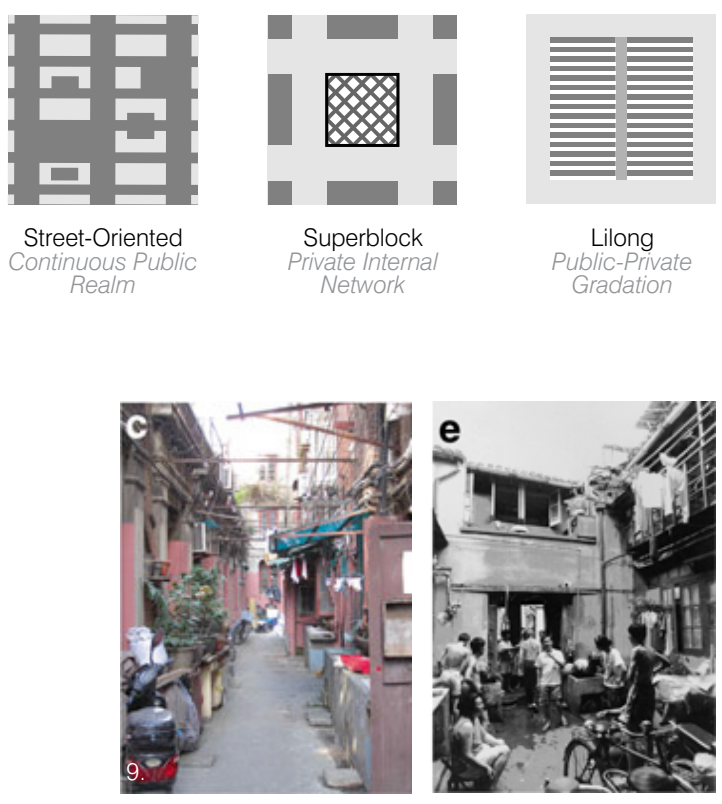

Lilong
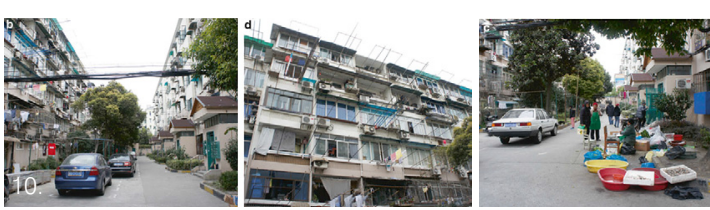

Danwei With its hierarchy of spaces creating a gradual threshold between vublic and plivate space, each cell of the lilong and danwei proReform Era this transition has become extremely abrupt and block consists of a much higher population. 
from the home and, in turn, increased car use. A greater consideration for the functions provided would produce a more walkable environment than what is currently produced by developer-driven growth of cities.

Again it may be valuable to compare the Reform Era superblock with the Neighbourhood Unit. Like Perry's Neighbourhood Unit, the Chinese superblock discourages access by non-residents. Its gated boundary clearly separates arterial traffic from local traffic by providing an independent network of roads on the interior of the block. While this abrupt distinction in many ways isolates the residents and impedes pedestrian movement between blocks, the interior of the block, though lacking in amenities, remains relatively pedestrian-friendly. Similarly, the Neighbourhood Unit promoted walkablility through the hierarchical separation of speeds and modes of travel as well as by limiting the overall size of the development to a walkable radius. Significantly, the provisions Perry made for commercial activity around the perimeter of his unit ensures a self-sufficiency that is frequently absent in the Chinese superblock. Both the walkability and mix of uses associated with Perry's Neighbourhood Unit is consistent with New Urbanist principles while preserving the fundamental principle of enclosure. It could therefore inform an adapted model of cellular development for China.

An Adapted Model of Urban Development

In order to address potential shortcomings in the development of Chinese cities in the Reform Era, the design portion of this thesis explores

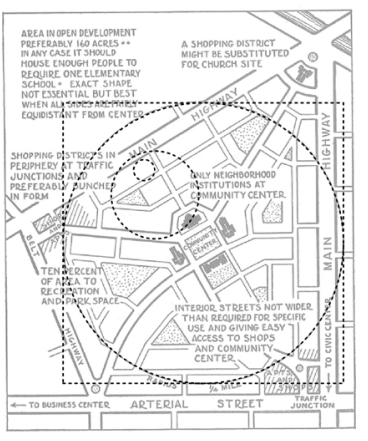
64 ha (160 acres)

5000 - 9000 residents

1600 units

25 UPH (10 UPA)
7290 residents (30 sq.m.jperson) 2430 units (3people/unit) $389 \mathrm{UPH}(158 \mathrm{UPA}$

The population density is much higher in superblock than Perry's Neighbourhood Unit. Similar in population, over four superblocks fit within same walkable region. However the provisions for commercial activity around the perimeter of the unit ensures a self-sufficiency that is frequently absent in the Chinese superblock. 
"adaptive" models of cellular urbanism. The goal is to incorporate many of the principles advocated by the New Urbanists without sacrificing elements crucial to the success of the model in the Chinese context. Adaptations should discourage the use of the car by incorporating a wider range of uses.

The adapted model will maintain the average block size and density of current development as it is practical for accommodating the rate and size of population growth that is projected for cities. As the solar orientation of residences in China is institutionalized in regulations and to a certain extent expected, housing should be configured to maintain solar exposure to a majority of units. To improve walkability and decrease the need for trips by car, the adapted model should introduce the possibility for different functions in close proximity to residences. A more permeable urban form is sought to connect residents both socially and physically to the rest of the city and allow a greater interaction

between residents of different developments. At the same time, a sense of security for residents should be established by maintaining some distinction between residential complexes and the rest of the city. Finally, the adapted model should serve to foster a more intimate sense of community among groups of residents than is currently afforded by the large populations of residential enclaves.

\section{Methodology}

The development of a prototype for adapted urban form is based on models of current Chinese development and idealized Western form.
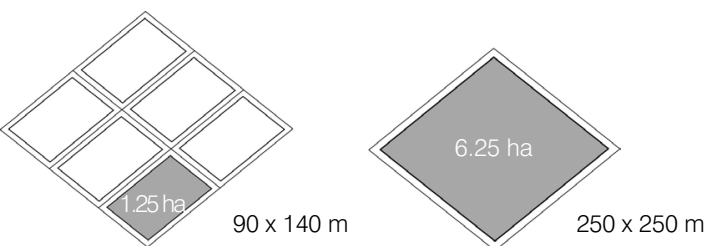

Block Size
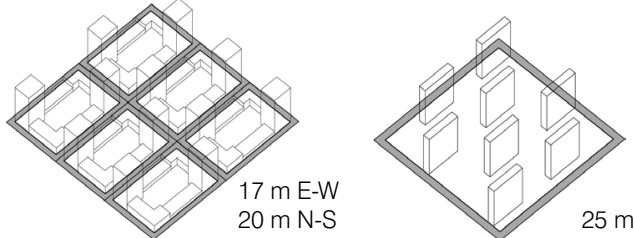

$25 \mathrm{~m}$

Street Network
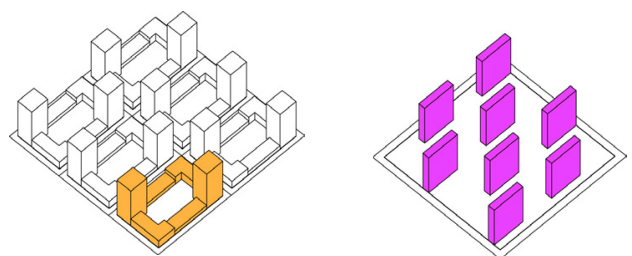

New Urbanist Planning vs. Chinese Superblock 
These models are compared graphically and numerically to inform an adapted model. Incorporating characteristics of street-oriented urbanism, historical Chinese forms, and Western superblock concepts, the two models are manipulated and combined in different ways, generating various iterations. The iterations are then compared and evaluated based on their adherence to the aforementioned criteria. One iteration has been selected to be developed in greater detail. notes

1. Congress for the New Urbanism, Natural Resources Defense Council, and the U.S. Green Building Council LEED 2009 for Neighbourhood Development, xi.

2. Ibid.

3. Ibid., xvii.

4. Abramson, "Haussman and Le Corbusier in China",

5. Peter Calthorpe, "Weapons of Mass Urban Destruction", 70

6. "Chenggong New Town," accessed March 30, 2015 http://www.calthorpe.com/chenggong

Deconstructing the Superblock $\mid 44$ 


\section{Deconstructing the Superblock}

In order to compare and contrast the characteristics of both street-oriented and cellular urbanism, two standard models will be used. One is based on New Urbanist principles as translated through LEED ND while the other is a standardized Chinese superblock. Block sizes, densities, street networks, open space, and building diversity of the two models are compared by way of formulating a hybrid approach to urban development. The area of the Chinese superblock is approximately six times that of the Western block. The standard block in China is roughly square in shape, and the north-south and east-west streets surrounding it are equal in width. The Western model consists of major north-south streets and minor east-west ones. While both of these streets are narrower than those bounding the Chinese superblock, the street dimensions relative to the area of the block are greater. As a result, there is more street space per block in the Western model. This reflects a greater emphasis on public space in street-oriented urbanism than with the Chinese superblock, where open space is largely contained within the block.

In addition to being expedient from a construction perspective, the decision to build out the Chinese superblock as a repetitive series of high-rises reflects the search for an optimal relationship between density, percentage of open space, and access to sunlight. With a mix of building heights, the Western model has a larger building footprint, less open space than the Chinese superblock, and the units within it may not all
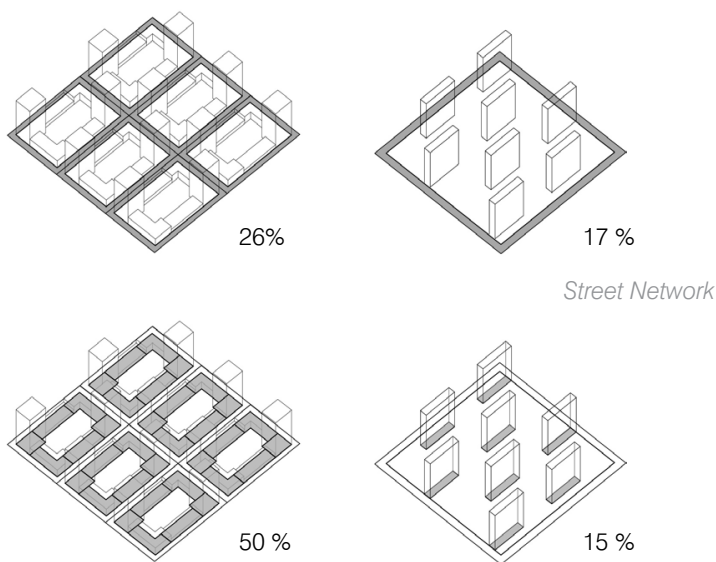

Building Footprin
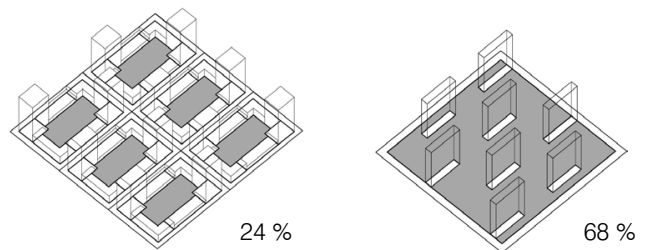

Interior Open Space

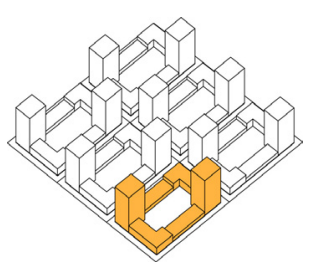

1.

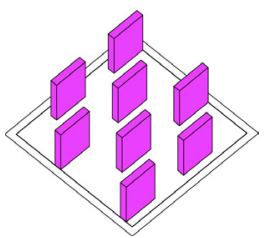

New Urbanist Planning vs. Chinese Superblock 

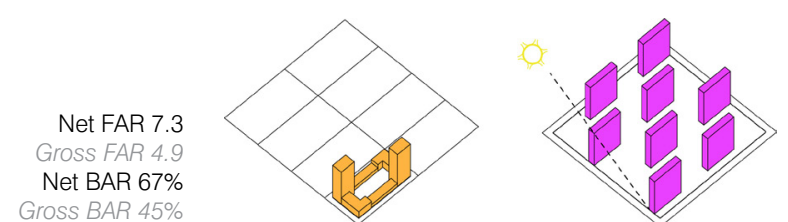

Standard Block

Net FAR 3.5

Net BAR 18\%

Gross BAR 15\%
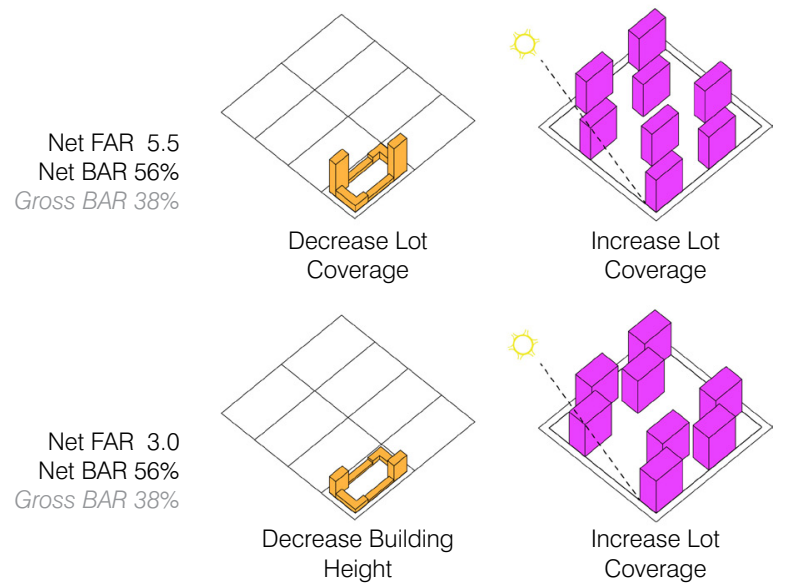

Net FAR 5.5

Net BAR 20\%

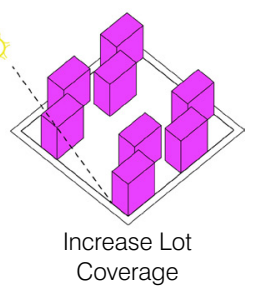

Net FAR 8.0

Net BAR 30\%

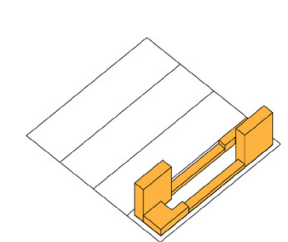

Increase Block Size

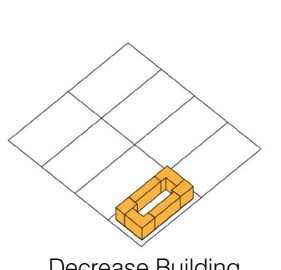

Decrease Building

Diversity

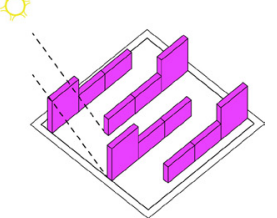

Increase Building Diversity

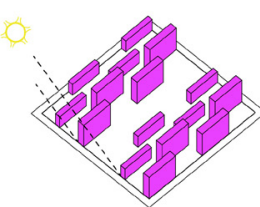

Increase Building Diversity
Net FAR 3.0 Net BAR 12.5\%

Net FAR 3.0 Net BAR 18.7\%

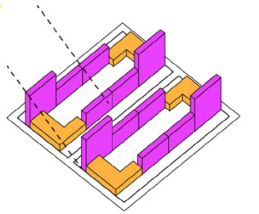

Increase Block Size +

Increase Building Diversity
Net FAR 3.6
Net BAR $30 \%$ Gross BAR 25\%

Hybrid Block 
receive the required minimum amount of sunlight. The large expanses of open space between buildings in the Chinese superblock are largely defined by landscaping features.

In order to arrive at a hybrid model that incorporates characteristics of both Chinese and Western planning, the standard models were manipulated to vary density (calculated as FAR or Floor Area Raito) and lot coverage (calculated as BAR or Building Area Ratio) (Figure 2). The general configuration of each model - hugging the perimeter in the Western model and spaced out according to requirements for minimum solar exposure in the superblock model - was preserved while bringing FAR and BAR values closer together. More diversity is introduced in the Chinese model by breaking down some of the towers into buildings of different heights while keeping them far enough apart to meet solar exposure requirements (Figure 3). While overall density is maintained, this increases the building footprint in the block, bringing the amount of open space closer to that of the Western model. Low-rise commercial blocks are introduced into the Chinese model and arranged to frame space within the block, creating smaller "sub-blocks" that approximate the smaller perimeter blocks of the traditional Western city and further reducing open space.

Figure 4 illustrates several iterations of patterns of multi-height towers and low-rise commercial blocks. In each of these alternatives, floor area remained relatively constant while BAR and building configuration varied, resulting in different patterns of open space. By breaking

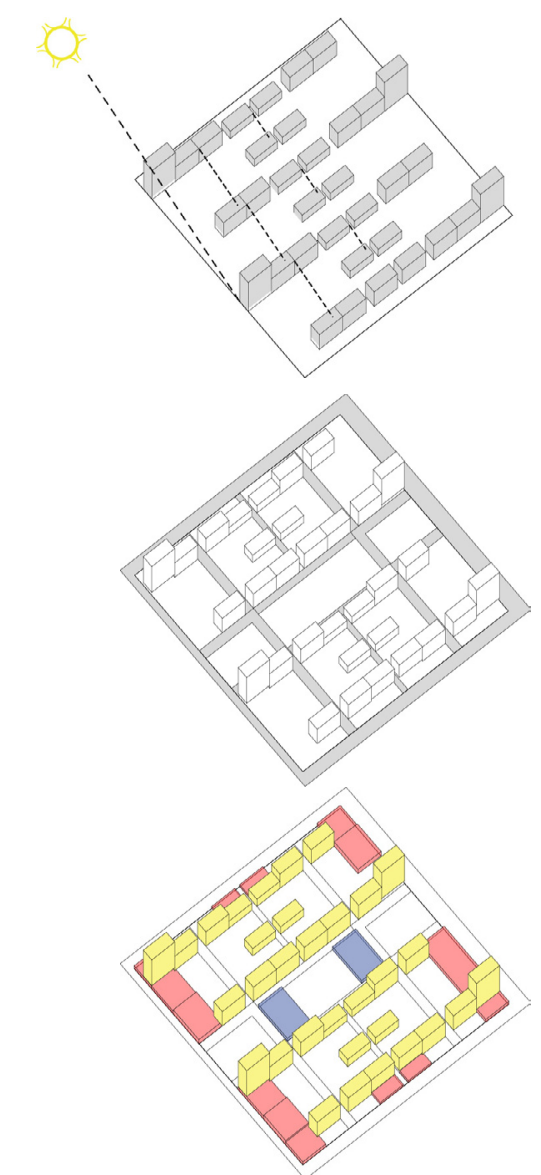

Towers are broken down into buildings of different heights while maintaining enough spacing to meet solar exposure requirements. Low-rise commercial blocks and a differentiated internal network are introduced and arranged to frame space within the block. 


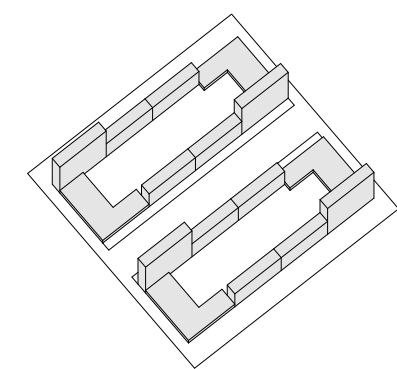

BAR $28 \%$

FAR 3.5

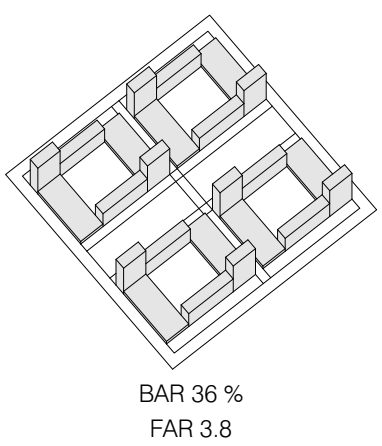

FAR 3.8

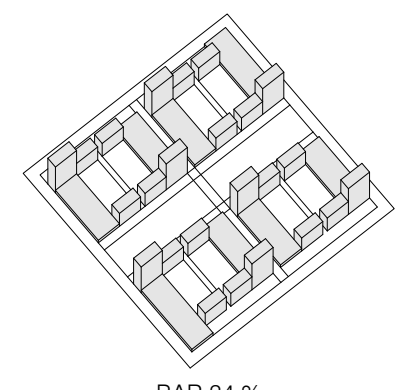

BAR $34 \%$

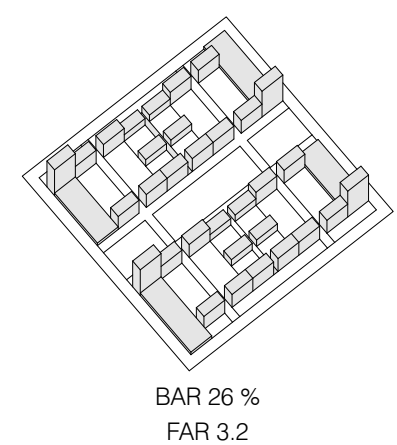

FAR 3.2

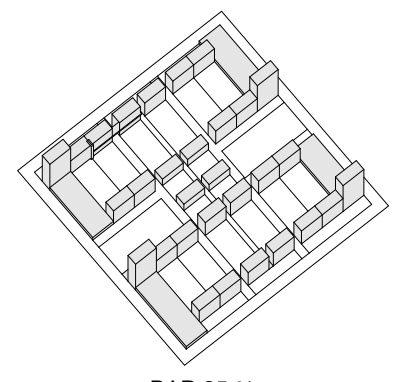

BAR $25 \%$

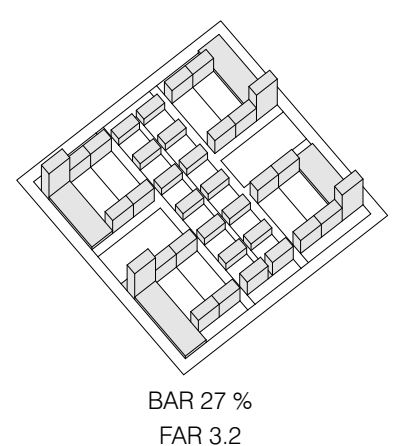

FAR 3.2

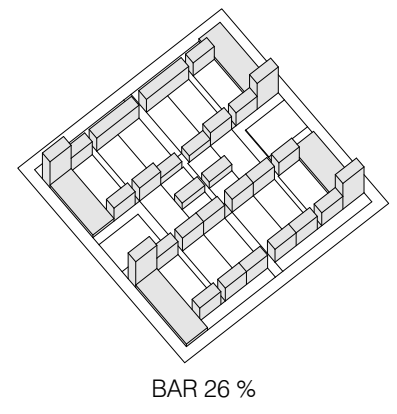

FAR 3.2

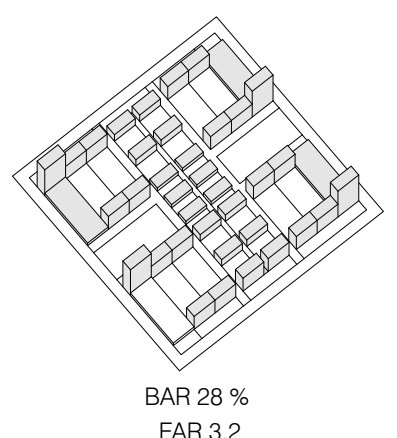

FAR 3.2 
down the towers of the superblock in different ways, different levels of enclosure and openness are created within the block. While buildings enclose some spaces, others are open to streets, creating more levels of differentiation between public and private areas. The introduction of local vehicular streets increases the overall percentage of space dedicated to streets, bringing it in line with the idealized Western model (Figure 5). Streets within the block, however, would remain privately developed and therefore independent of the larger (square) grid of public streets. Different patterns of internal streets were explored by way of introducing a greater level of permeability into the block without permitting traffic to cut completely through it. 


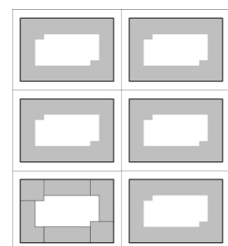

$50 \%$

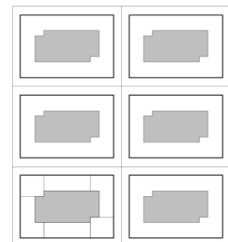

$24 \%$

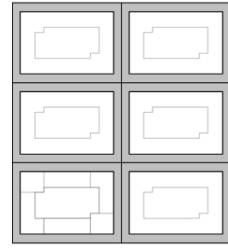

$26 \%$

$100 \%$
Chinese Superblock

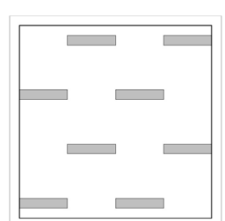

$15 \%$

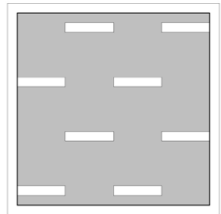

$68 \%$

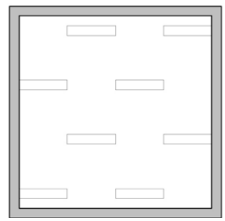

$17 \%$

$100 \%$

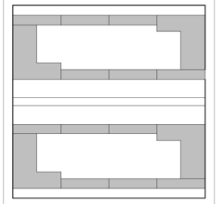

$28 \%$

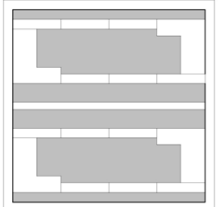

$52 \%$

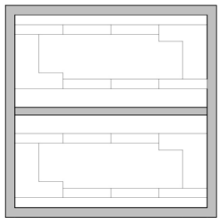

$20 \%$

$100 \%$

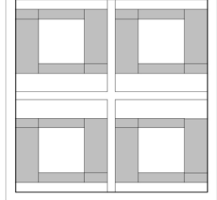

$36 \%$

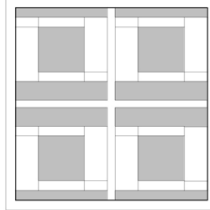

$41 \%$

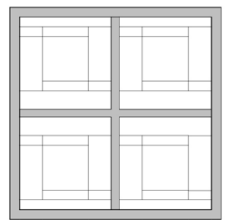

$23 \%$

$100 \%$

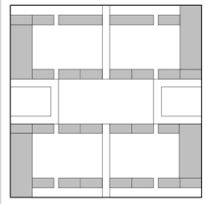

$24 \%$

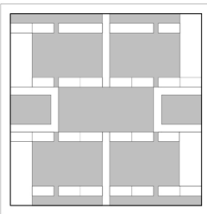

$52 \%$

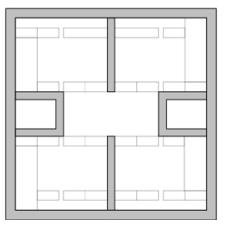

$24 \%$

$100 \%$

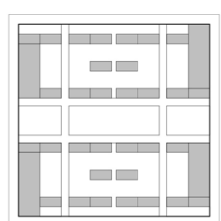

$26 \%$

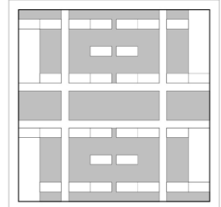

$32 \%$

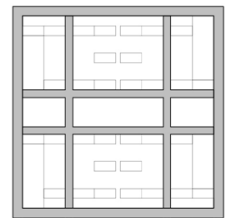

$42 \%$

$100 \%$
Building Footprint (BAR)

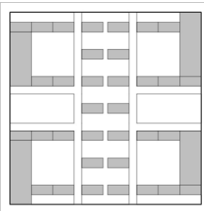

$27 \%$

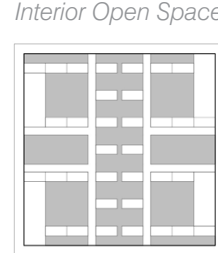

$45 \%$

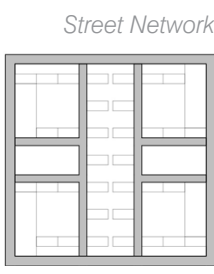

$28 \%$

$100 \%$ 
The Adapted Superblock

One iteration was used to explore in greater detail how the concepts for a hybrid model could function as a unit of urban development in China. One configuration of residential towers of various sizes was chosen and a basic strategy for a street network and functional layout is presented.

The adapted model deploys a hierarchical pattern of buildings and streets to achieve different levels of "publicness." In contrast to the inward focus of the current gated superblock (where even spaces adjacent to streets are walled off from streets), the adapted model engages the city to a greater degree by enabling selected spaces and functions to be used by residents and non-residents alike. Other areas of the block would remain reserved for residents. Buildings are configured into smaller "sub-blocks," creating a sense of enclosure at a smaller scale within the block while enabling certain areas to be more permeable to non-residents.

Spaces within the block are targeted to progressively smaller groups of residents, the size of spaces decreasing in proportion to the number of residents they are intended to serve. Accordingly spaces within the block differ in accessibility and enclosure. A hierarchical system of functions within the block is established, serving residents as well as the larger community. Functions are classified as inter-block (shared between blocks), intra-block (shared within a block), or sub-block
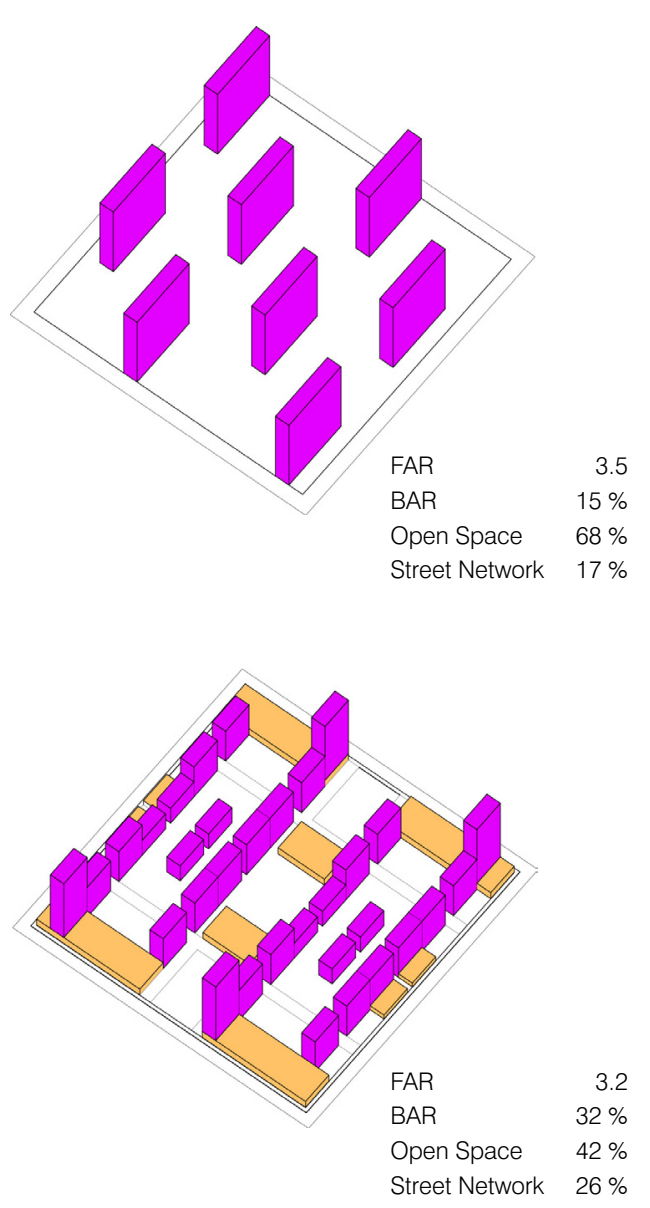

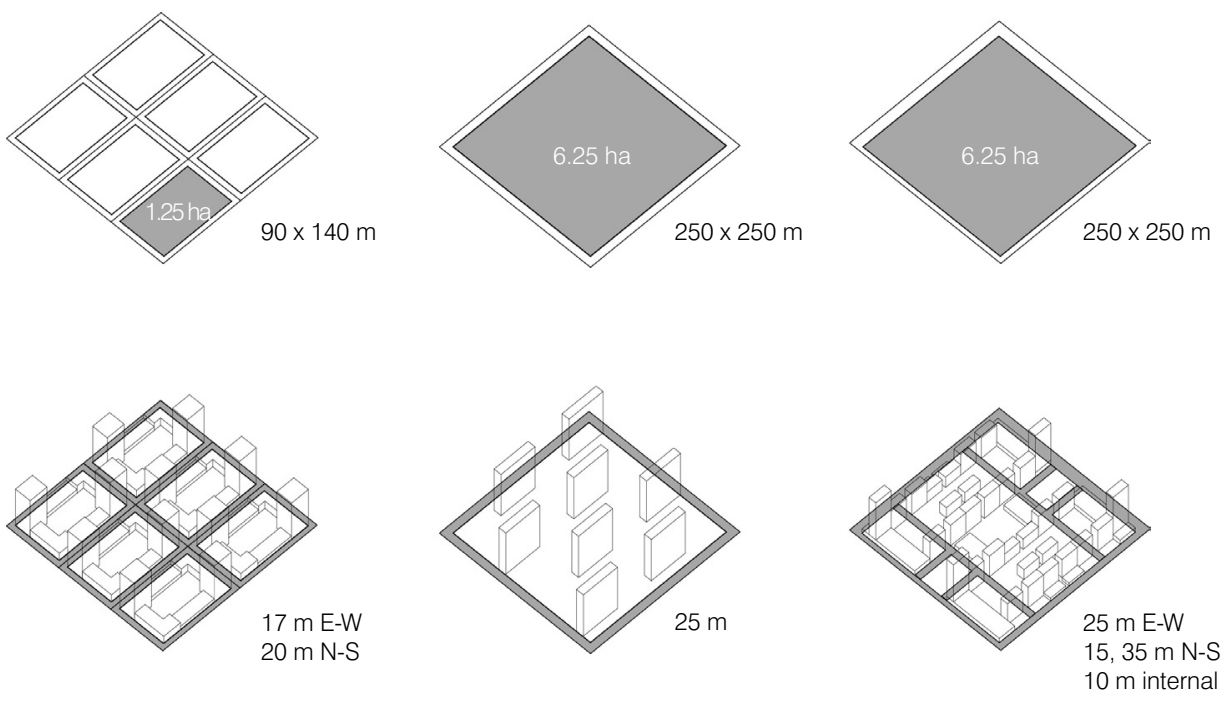

Street Network
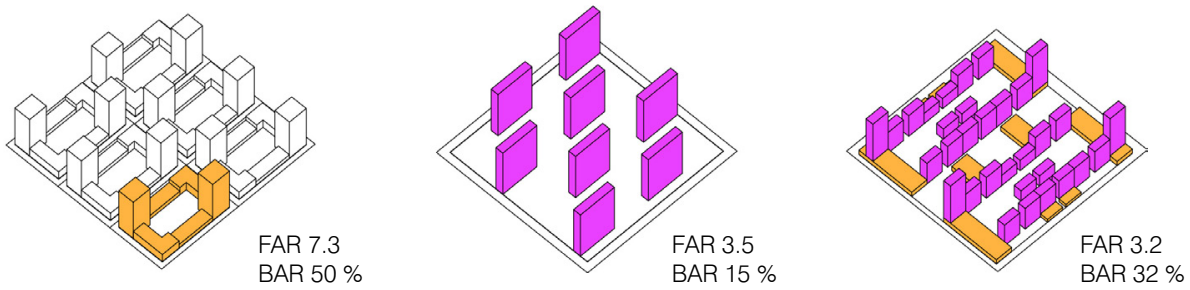

Standard Block 
(shared between enclaves of a few buildings) (Figure 8). These smaller enclaves create a more intimate sense of community by breaking the population of the superblock down into smaller collectives while allowing other areas of the block to be more permeable to the rest of the city. In addition to degree of "publicness", functions are defined by how many people they serve. A given function would fall into a public, semipublic, or semiprivate zone depending on how many people a given function needs to serve.

Functions within the block would emphasize these varying degrees of publicness by varying in type, density, and position within the block (Figure 9). Commercial buildings along north-south public streets would be of higher density and serve both residents and non-residents. These north-south streets provide access to non-residents on semipublic roads, forming more permeable east and west edges. Smaller shops are located along east-west streets which would be more locally oriented,

i.e., operated by and catering to residents. Access points for residents would be provided along the north and south edges of the block (i.e., east-west streets), leading directly into semiprivate areas enclosed by residences (Figure 10). Non-resident vehicular access routes are configured in "U"-shaped loops to prevent through traffic from penetrating the block, but semipublic pathways allow the general public to cut through blocks on foot. Community functions like schools would be located toward the centre of the block, easily accessible from both non-resident access routes and the enclosed semiprivate zones.

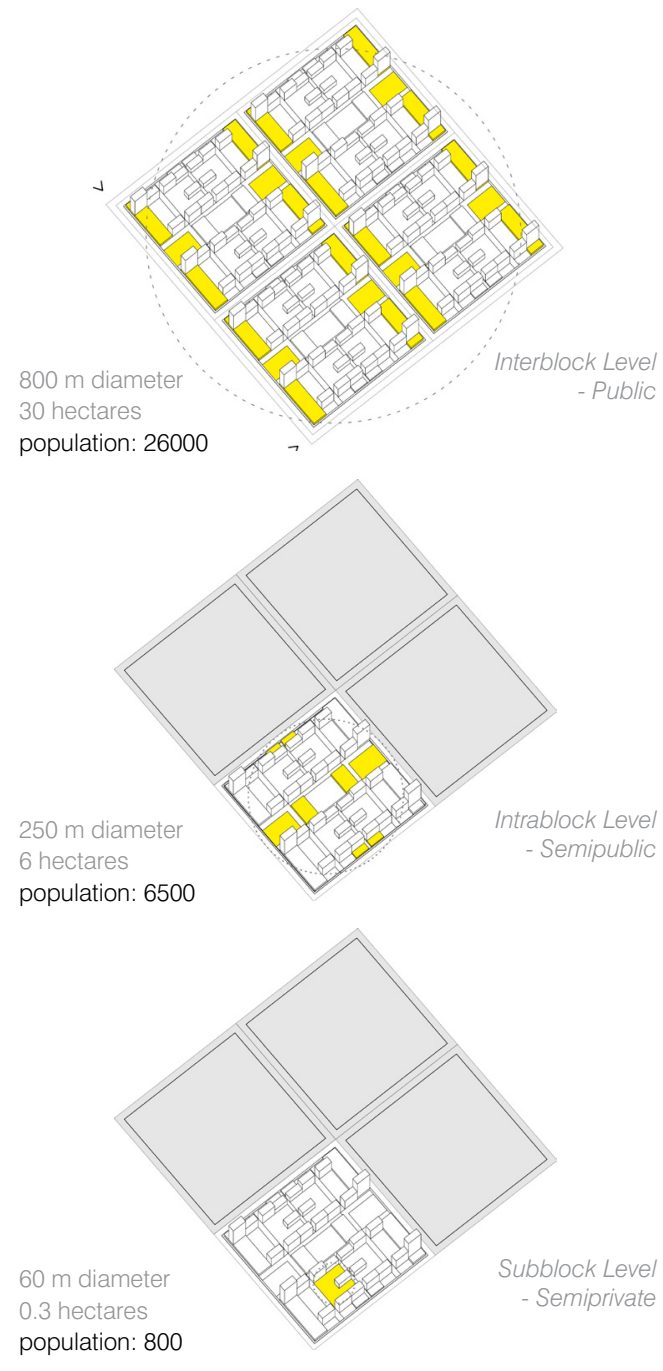




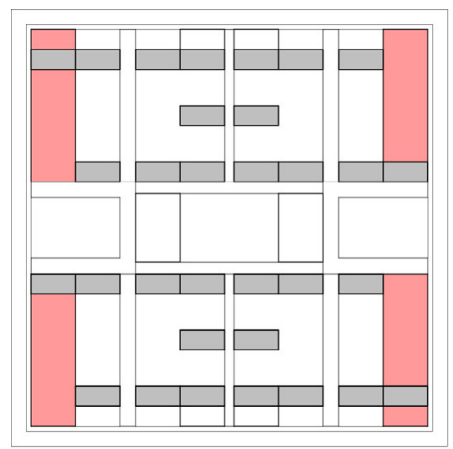

N-S Streets

Major Commercial Space

9

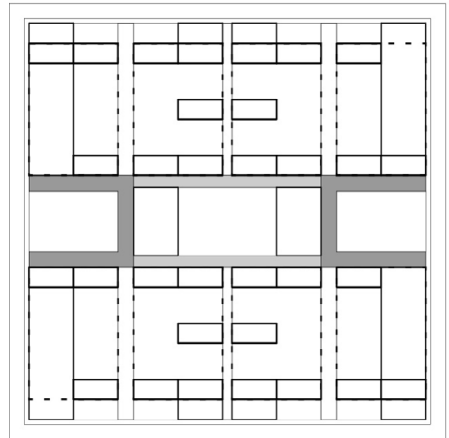

Non-resident Semipubics and Pedestrian Access

10.

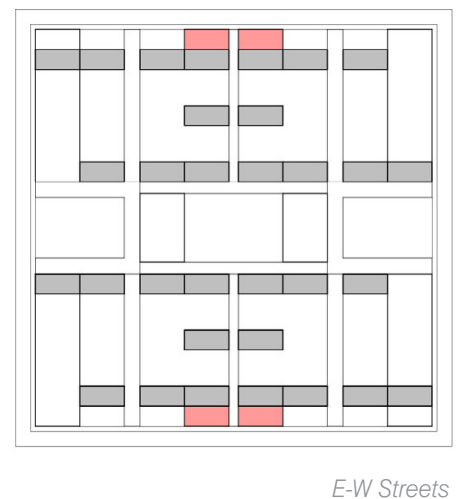

Minor Commercial Space

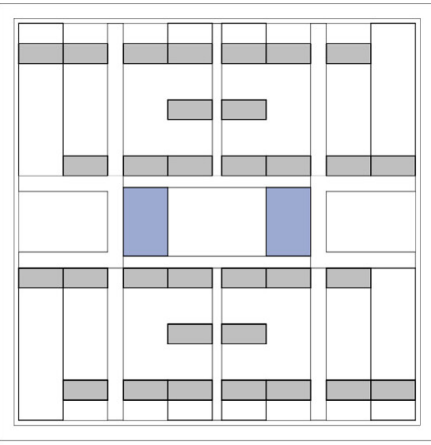

mmunity $F u$

Adapted Model Analysis: Functional Hierarchy

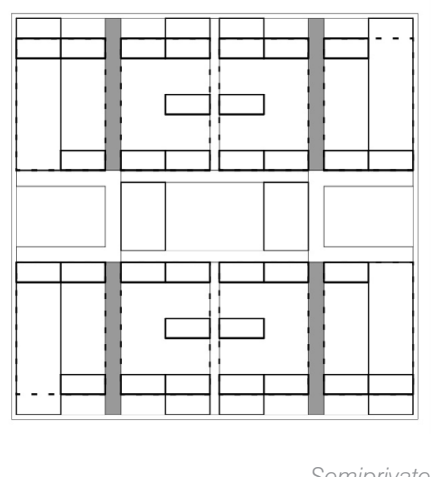

Resident Vehicular Access

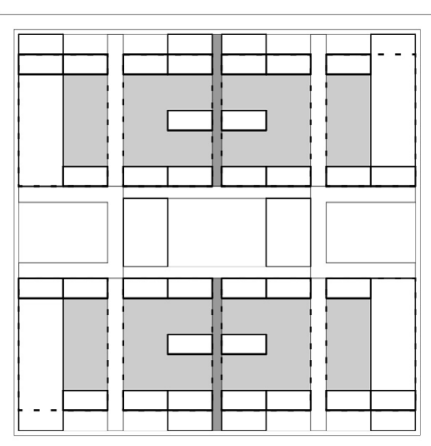

Resident Pedestrian Access and Open Space

Adapted Model Analysis: Street Hierarchy

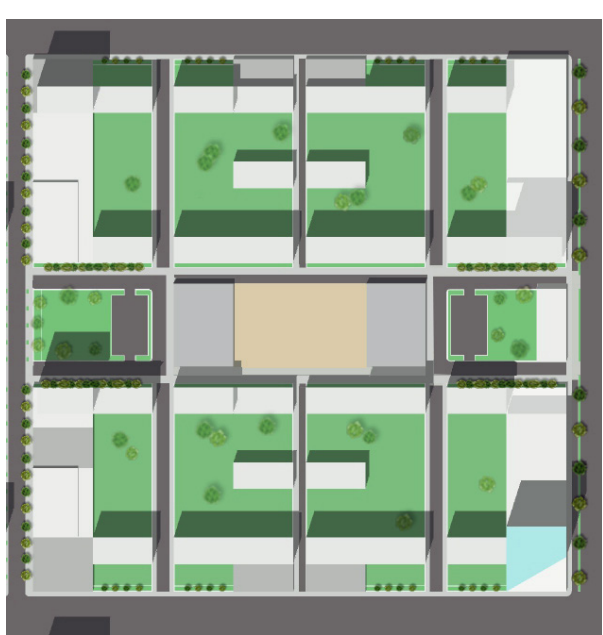

Deconstructing the Superblock | 54 
The adapted model was also compared to Clarence Perry's Neighbourhood Unit to assess its walkability. Because it's not as dense, the Neighbourhood Unit accommodates a similar population as a Chinese superblock (approximately 6000 people) in a much larger block, which can be traversed on foot in 10 minutes (800 metres across) - a comfortable time/distance to walk to complete daily errands as opposed to using other means of transportation such as a car (Figure 11). A group of four Chinese superblocks fall within this boundary and thus form a walkable region. Within the adapted model, this grouping represents a larger unit of development at which to plan the distribution of certain amenities and social infrastructure that may be shared amongst blocks while remaining reachable on foot. The location of services (such as schools and recreational facilities) may be determined based on density (per amount of population) or by walkability (located at specified intervals).

Similar to the roads within the block, the public streets separating blocks become more differentiated. 6.25 hectare-superblocks are combined into groups of four and distinctions are made between the streets separating them and those outside (Figure 12). At a width of 15 metres, every second north-south street is narrow relative to typical Chinese streets. The commercial functions along these streets would be a smaller scale mix of shops and stores. Serving the blocks on either side of it, which lie in the 10-minute walkable circle, these smaller-scale
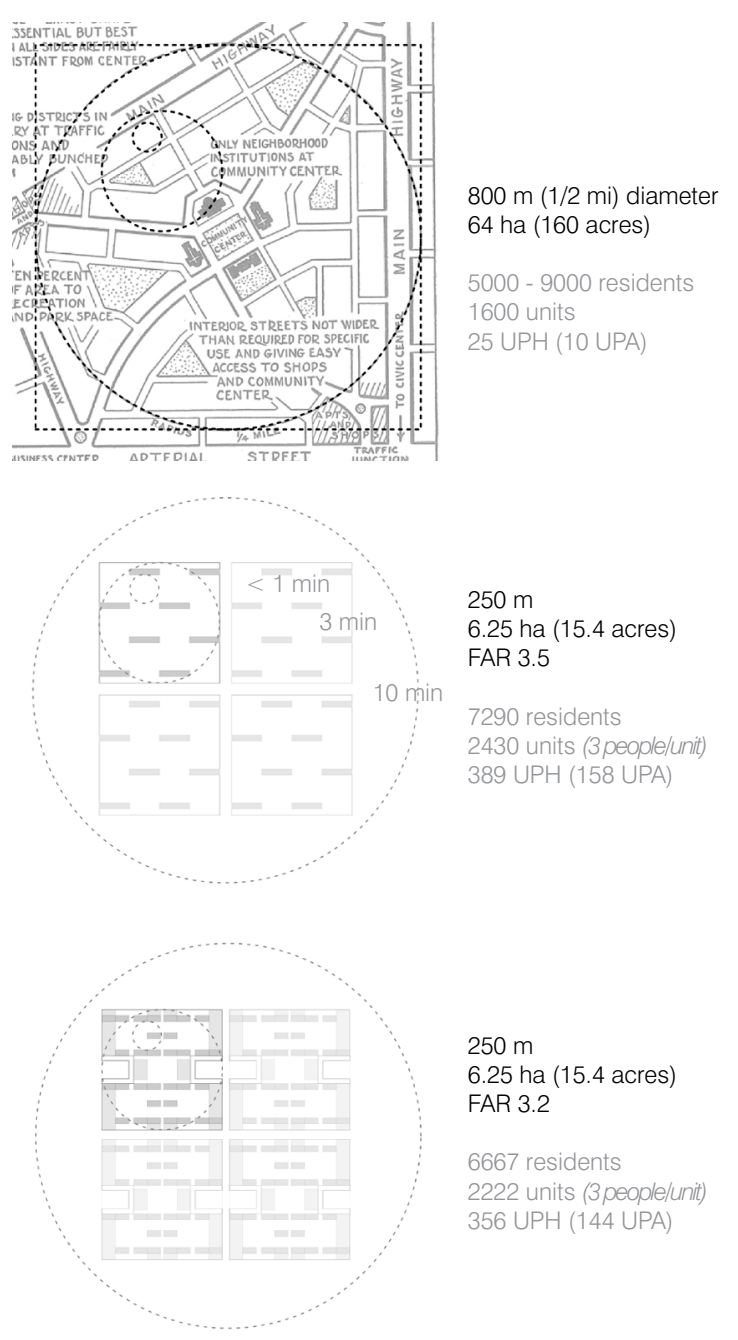

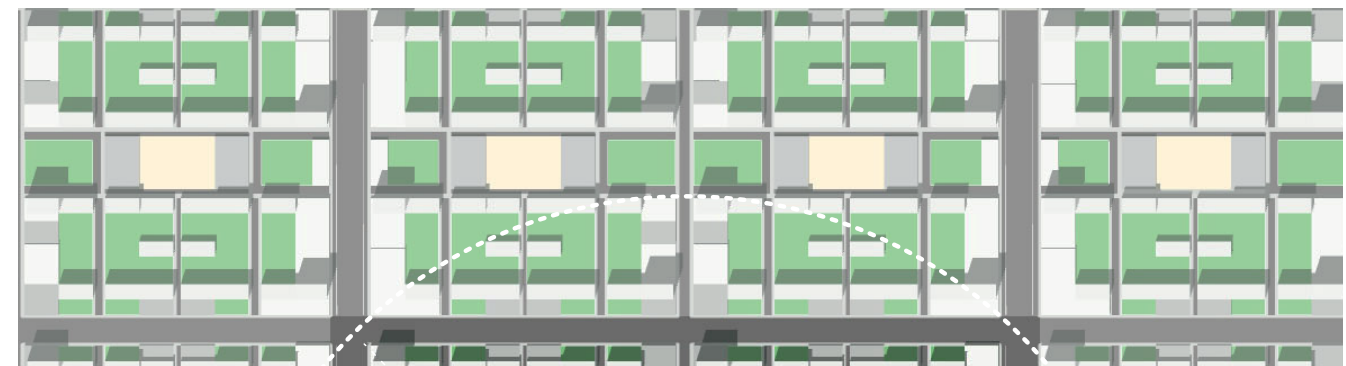
प
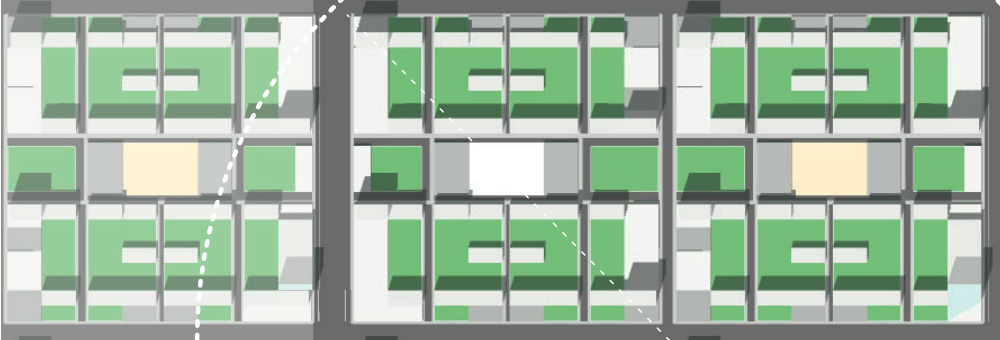

$\therefore=-1$
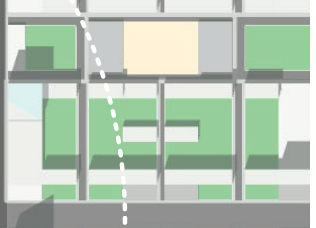

Secondary E-W Street
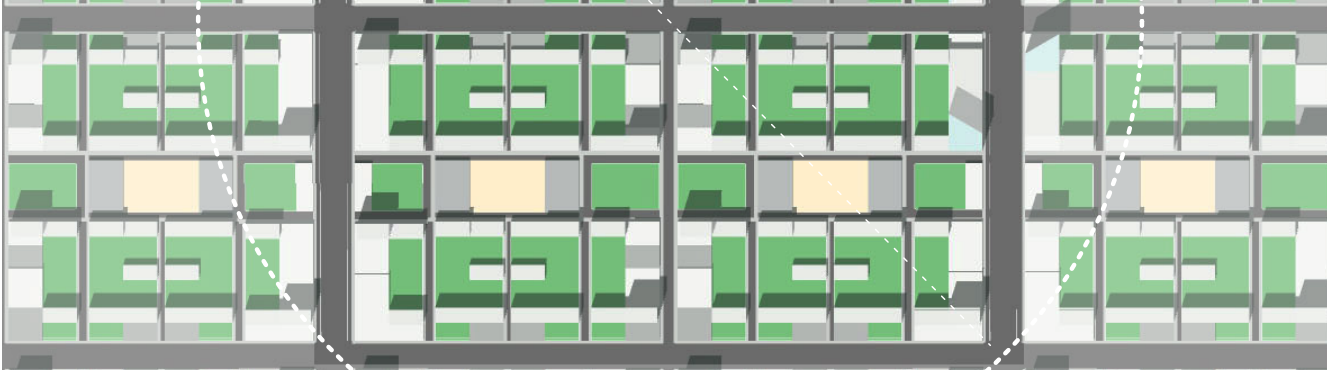

Resident block access
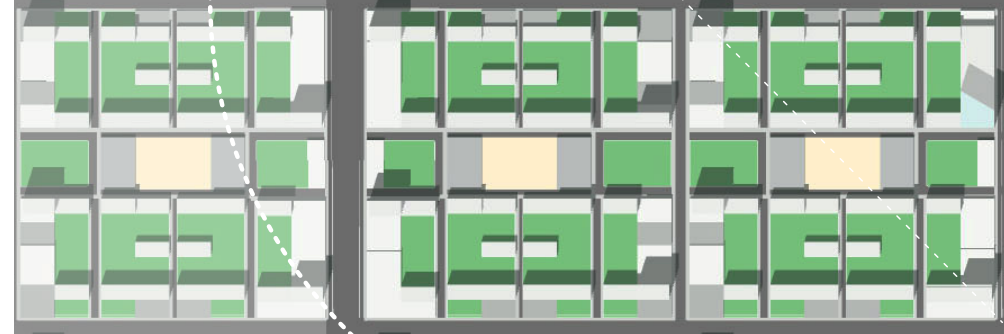

Shops serving/owned by block

residents

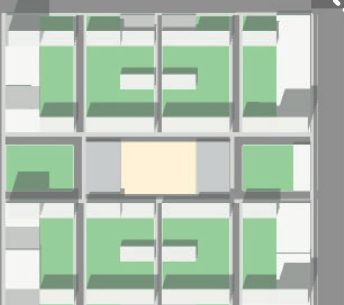

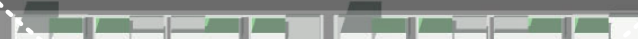
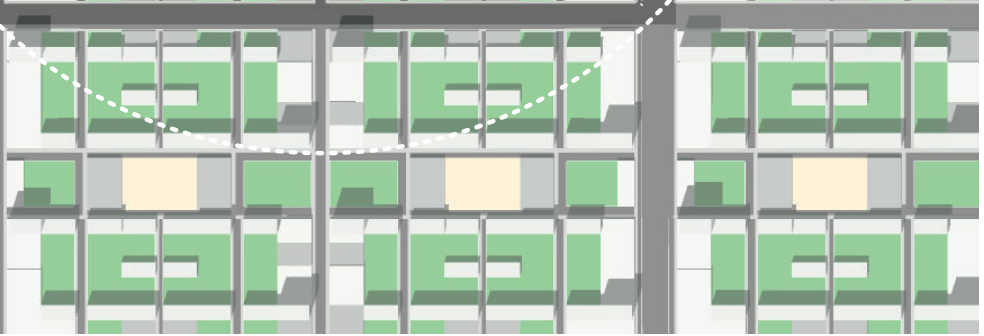

$100 \mathrm{~m}$

Primary Arterial Road

Secondary N-S Street

Transit Stops

Smaller more frequent shops

Large-scale

and services

Neighbourhood Scale Development Pattern

Deconstructing the Superblock $\mid 56$ 
streets would accommodate a lower speed of traffic and would be more pedestrian-oriented. Other north-south streets would be classified as

major arterial roads with a width of 35 metres. The commercial activity along these streets would be of higher intensity and potentially more infrequent, i.e., on the order of major supermarkets, department or big box stores. These functions would serve a larger population travelling greater distances. The arterials would thus be oriented toward a higher speed of traffic. Faced onto by residences and providing block access for residents, east-west streets would be principally residential in nature. The semipublic paths through the centre of blocks allow for a denser pattern of accessibility for pedestrians by potentially allowing the general public to cut through blocks, forming more frequent continuous routes through the city in the east-west direction.

An even larger scale - that of the district - forms the basis for planning rapid transit (Figure 13). Rapid transit stations are provided at such a scale so as to allow areas of the city outside the walkable region surrounding a given housing unit to be accessible without a car. Transit stations are to be planned at every second north-south arterial road, at a walkable spacing of 1100 metres (a 550 m radius corresponding to a 14 minute walk). At this radius, stations would be located at intervals along every fourth east-west street. These east-west streets would create a grid of arterial roads superimposed over the smaller scale square grid of public streets. This creates another tier of differentiation for functions. Commercial areas surrounding transit stops would be of highest intensity,

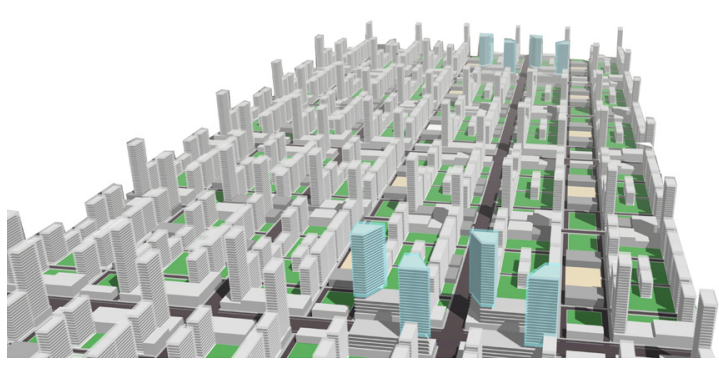


acting as hubs and consisting of shopping malls and large-scale office complexes. As recommended in LEED-ND, such a pattern of development fosters high densities around transit stops and encourages transit use in lieu of driving.

The phasing of development reflects the nature of functions (Figure 15). Residences would be the first buildings to be constructed, enabling developers to make a profit. While clearly designated in the master plan areas for commercial functions would be gradually built and rented out as there is population to support it. This would result in a residential building stock that is more pragmatic, responding to the profit motives of developers, and commercial buildings that are more varied and diverse.
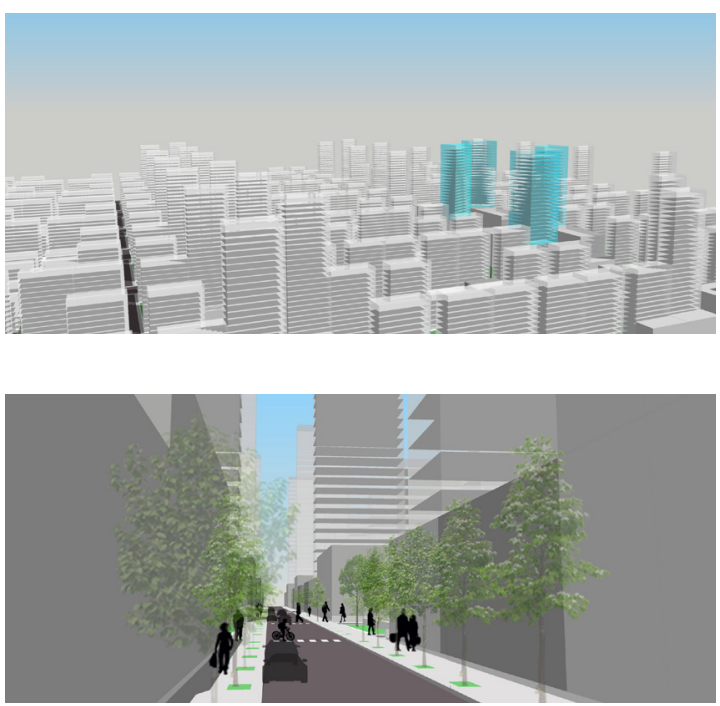

Areas for commercial functions would be gradually built and rented out as there is population to support it. This would result in a residential building stock that is more pragmatic, responding to the profit motives of developers, and commercial buildings that are more varied and diverse.

Pragmatism + Diversity 


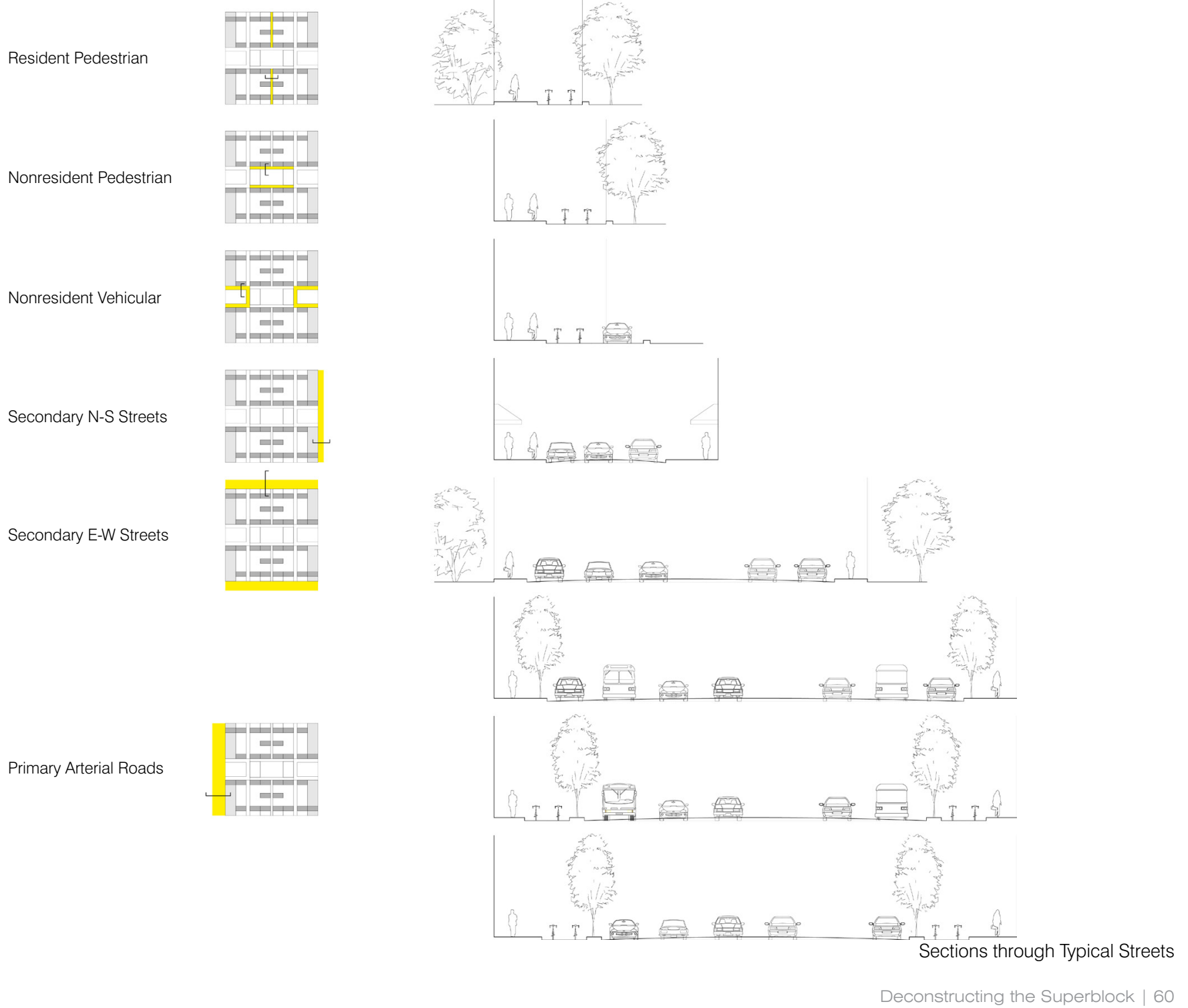



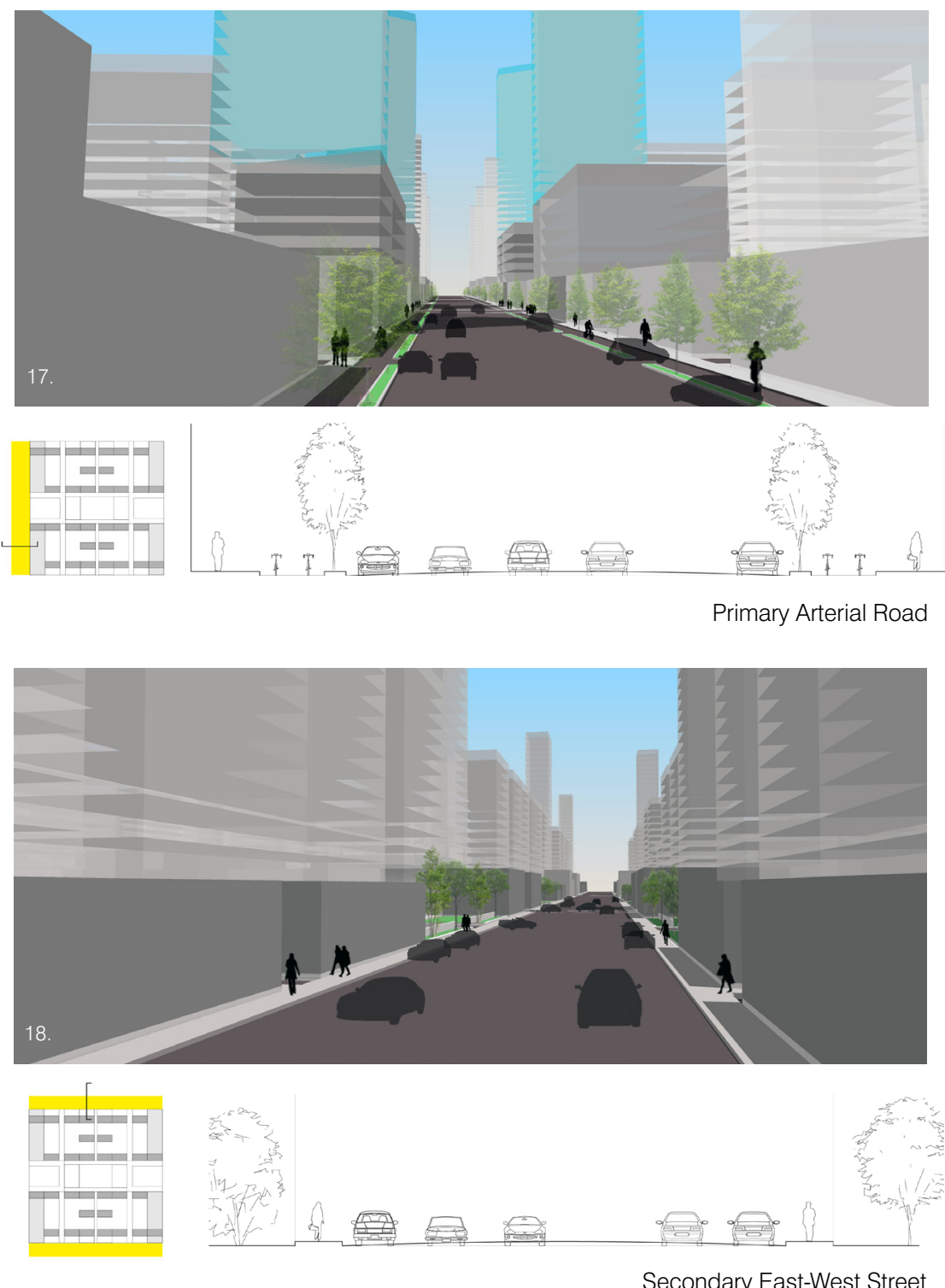


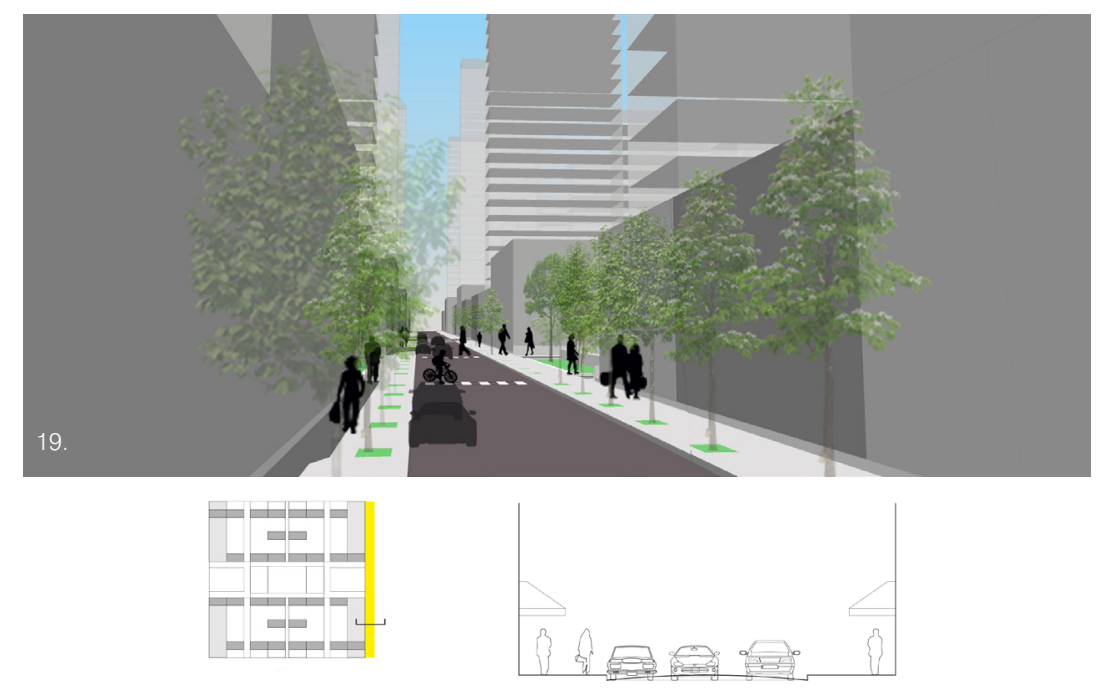

Secondary North-South Street

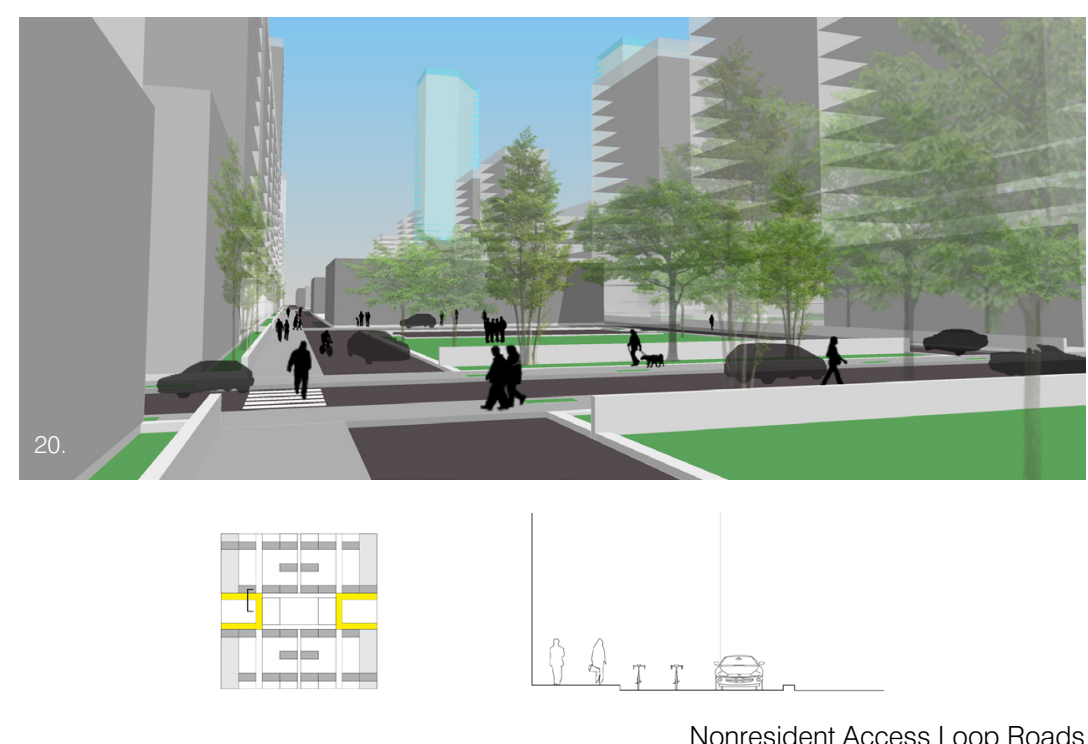

Nonresident Access Loop Roads 


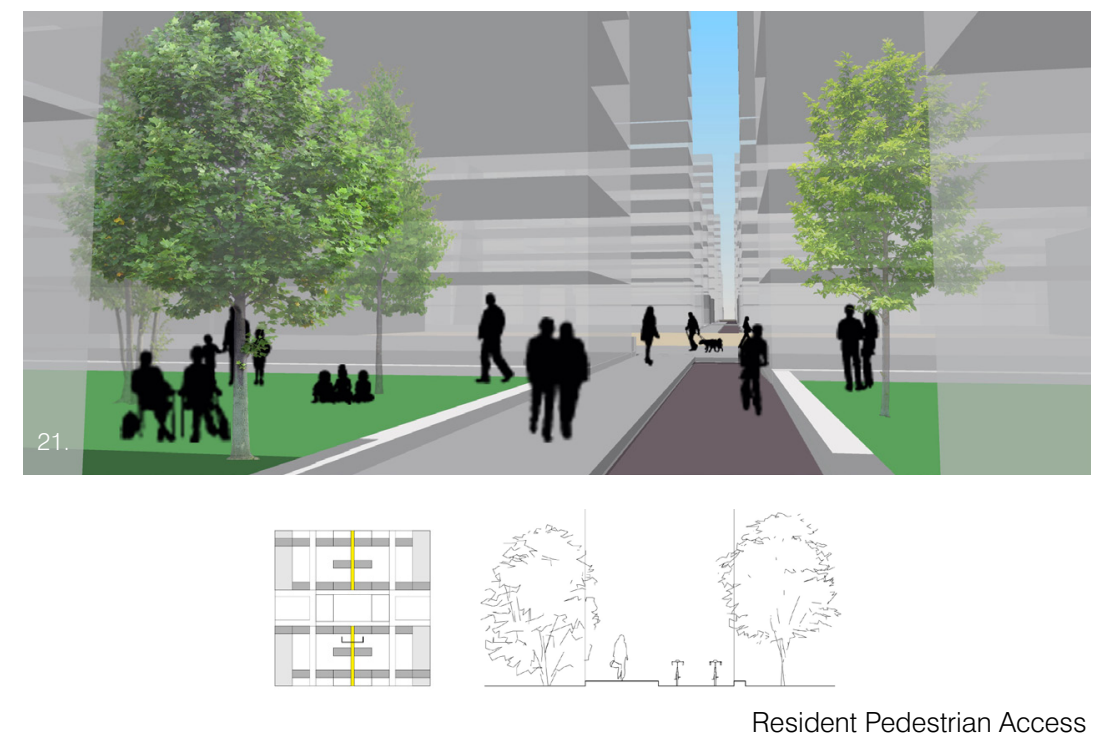




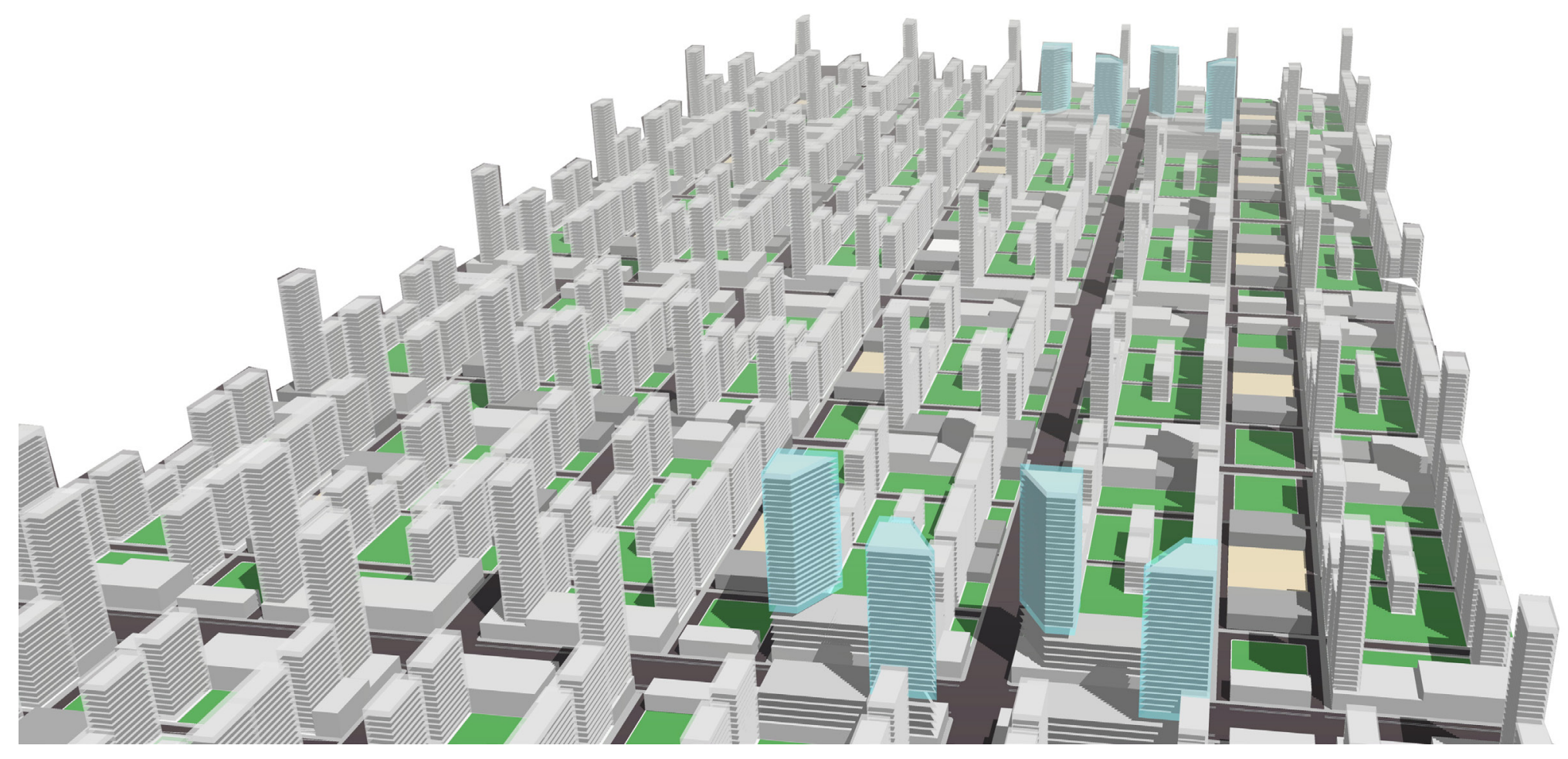


Learning from the West: The Validity of a Hybrid Approach However expedient or inevitable, the form of much of the development occurring on the periphery of Chinese cities would appear to be problematic. The repetitive blocks of high-rise housing corralled into superblocks are eerily reminiscent of the urban re-redevelopments that appeared under the thrall of Modernism in the decades following WWII. Excoriated by critics like Jane Jacobs, many high-profile European and American tower ensembles fared poorly and have since been demolished. Streets pushed though superblocks support a finer-grained urban fabric where towers once stood. There is broad consensus in the West that buildings in cities must address and engage streets, especially socalled fabric buildings like housing.

On the other hand, current approaches to the build out of Chinese cities draw heavily on precedents in Hong Kong and Singapore, where "tower-in-the-park" planning is not only the norm, but has worked relatively well.

This thesis has used the experience of superblock planning in the West - in both urban and suburban contexts - as a counterpoint from which to examine Reform Era superblock development in China. Arguably there is no real precedent for what is going on in China. First, there is no modern equivalent in the West to the rapid rate at which China is urbanizing. Second, although development patterns in China share 
formal characteristics with postwar modernist developments, significant cultural, geographic, and demographic differences distinguish Chinese superblocks from their Western counterparts. Thus the critiques that have been made against modernist "tower-in-the-park" development are not necessarily transferrable without first acknowledging such differences. Further, as high densities characterize both urban and suburban areas in China, development in China defies classification as either urban or suburban from a Western perspective.

That being said, and especially considering the scale and rate at which superblock tower ensembles are being constructed in China, it may be relevant to question their longer-term sustainability from a Western perspective. Economic reforms, modernization, globalization, and the move away from a classless society have made Chinese cities more vulnerable to the social and environmental problems with which many cities grapple. As it continues to urbanize, China may be able to learn from the experience of cities elsewhere.

In addition to looking to the West, this thesis has proposed that the past might provide clues to a more sustainable future. As such, this thesis includes a study of historical urban forms in China to better situate current approaches to the build-out of residential districts. As norms and expectations change in the course of China's rapid transformation, so too might the cultural relevance and resonance of certain practices. As China becomes more globalized, as the middle class grows in size and 
political influence, and as the experience of each generation diverges from that of the previous one, historically established notions like gating and enclosure may diminish in relevance despite having persisted across different eras. Indeed, consisting as it does of a scale of buildings and spaces never before experienced in China, the Reform Era superblock may already reflect such transition.

With a greater openness to the rest of the world, it may be argued that China is transitioning to a more individualistic society with desires for privacy and individualism similar to those in the West. ${ }^{1,2}$ While the superblock embodied the collective values of Chinese society in the past, it may no longer in the Reform Era where these values are weaker.

The transition of urban form between eras in the past (hutong to danwei, danwei to the Reform Era superblock) saw certain aspects persisting while others changed in tandem with shifts in cultural and social values. Similarly, the proposal for an adapted model attempts to uphold certain aspects of current development and look elsewhere to introduce others. The aim has been to produce a more flexible solution that will be resilient enough to account for and respond the societal changes associated with China's continued urbanization.

1. Wu, "Rediscovering the 'Gate' under Market Transition,'

Deciphering the Prevalence of Neighborhood Enclosure amidst Post-1949 Chinese Cities: A Critical Synthesis," 5 
Abramson, Daniel Benjamin. 2006. "Urban Planning in China: Continuity and

Change." Journal of the American Planning Association [H.W.Wilson - SSA] 72

(2): 197.

Abramson, Daniel Benjamin. 2008. "Haussmann and Le Corbusier in China: Land Control and the Design of Streets in Urban Redevelopment." Journal of Urban Design 13, (2): 231-256

Asian Development Bank. 2006. Urbanization and Sustainability in Asia: Case Studies of Good Practice. Manila: Asian Development Bank.

Baeumler, Axel, Ede ljjasz-Vasquez, Shomik Mehndiratta, eds. 2012. Sustainable Low-Carbon City Development in China. Washington DC: The World Bank.

Calthorpe, Peter. 2012. "Weapons of Mass Urban Destruction." Foreign Policy, 09, Issue 195: 68-71.

Calthorpe Associates. "Chenggong New Town." Accessed March 30, 2015. http:// www.calthorpe.com/chenggong.

Congress for the New Urbanism, Natural Resources Defense Council, and the U.S. Green Building Council. 2009. LEED 2009 for Neighbourhood Development. U.S Green Building Council, Inc.

Hall, Peter. 2002. Cities of Tomorrow: An Intellectual History of Urban Planning and Design in the Twentieth Century. Oxford: Blackwell Publishers.

Hassenpflug, Dieter. 2010. Urban Code of China. Birkhäuser Basel.

Hee, Limin. 2007. "Rethinking Shanghai's Urban Housing." Urban Design International 12, (2-3): 131-142.

Hsing, You-tien. 2010. The Great Urban Transformation: Politics of Land and Property in China. Oxford: Oxford University Press.

Huang, Youqin. 2005. "From Work-Unit Compounds to Gated Communities." In 
Restructuring the Chinese City, edited by Fulong Wu and Laurence J. C. Ma, 192-221. London: Routledge.

Huang, Youqin. 2006. "Collectivism, Political Control, and Gating in Chinese Cities." Urban Geography 27, (6): 507-525

Jacobs, Jane. 1961. The Death and Life of Great American Cities. New York: Random House.

Liang. Samuel Y. 2013. "Planning and its Discontents: Contradictions and Continuities in Remaking China's Great Cities, 1950-2010." Urban History 40, (3): 530-553.

Lu, Duanfang, and Taylor \& Francis Group. 2005. Remaking Chinese Urban Form: Modernity, Scarcity, and Space, 1949-2005. New York; London: Routledge.

Miao, Pu. 1990. "Seven Characteristics of Traditional Urban Form in Southeast China." Traditional Dwellings and Settlements Review: Journal of the International Association for the Study of Traditional Environments 1, (2): 35-47.

Miao, Pu. 2003. "Deserted Streets in a Jammed Town: The Gated Community in Chinese Cities and its Solution." Journal of Urban Design 8, (1): 45-66.

Miller, Tom. 2012. China's Urban Billion. London, New York: Zed Books.

Monson, Kjersti. 2008. "String Block vs Superblock Patterns of Dispersal in China." Architectural Design 78, (1): 46-53.

Pang, Wai Ki. 2006. "Urban Morphology of Traditional Chinese Cities in the Context of Modernization - A Case Study of Suzhou," 42nd ISOCARP Congress 2006 Cities between Integration and Disintegration.

Patricios, Nicholas. 2002. "Urban Design Principles of the Original Neighborhood Concepts." Urban Morphology 6.1: 21-32.

Qian, Junxi. 2014. "Deciphering the Prevalence of Neighborhood Enclosure amidst Post-1949 Chinese Cities: A Critical Synthesis." Journal of Planning Literature 29, (1): 3-19. 
Qin, Bo and Sunsheng Han. 2014. "Spatial Strategies for a Low Carbon City in China." In Transforming Chinese Cities, edited by Mark Y. Wang, Pookong Kee, and Jia Gao. Abingdon: Routledge.

Rowe, Peter G. 2005. East Asia Modern: Shaping the Contemporary City. London: Reaktion.

Sha, Yongjie et. al. 2014. Shanghai Urbanism at the Medium Scale. Heidelberg: Springer.

Wang, De, Li Zhang, Zhao Zhang, and Simon Xiaobin Zhao. 2011. "Urban Infrastructure Financing in Reform-Era China." Urban Studies 48, (14): 2975-2998.

Wu, Fulong. 2005. "Rediscovering the 'Gate' under Market Transition: From WorkUnit Compounds to Commodity Housing Enclaves." Housing Studies 20, (2): 235-254

Wu, Fulong, and Laurence J. C. Ma. 2005. Restructuring the Chinese City: Changing Society, Economy and Space. London: Routledge.

Wu, Weiping and Piper Gaubatz. 2012. The Chinese City. Abingdon: Routledge 


\section{Introduction}

Reuters/Stringer, Carlos Barria, "Pudong, Shanghai: 1987 to 2013," The Atlantic, www.theatlantic.com.

John J. Kim, "Designed in Chicago, Made in China," Chicago Tribune, http://apps.chicagotribune.com/news/chicago-architecture-in-china/ live.html.

4 Pier Alessio Rizzardi, "Real Estate in Chongqing," TCA Think Tank, http://tcathinktank.com/2014/08/16/chinas-city-making-process-investors-power-in-the-peoples-republic.

Matthew Neiderhauser, "Meandering Down the Pathway to Heaven,"

http://matthewniederhauser.com.

\section{Chapter 1}

Ruben Bergambagt, "The monotony of Chinese residential towers,"

Urban Vignettes, http://urbanvignettes.com/articles/anything-but-westernthe-monotony-of-chinese-residential-towers. John J. Kim, "Designed in Chicago, Made in China."

$3 \quad$ "NYC 14 1 th Street Looking West," http://en.wikipedia.org/wiki/14th_ Street \%28Manhattan\%29.

$4 \quad$ Ming Li, www.barrettwells.com.

5 Bing Maps, https://www.bing.com/maps.

7 Diagram by author

8 Pier Alessio Rizzardi, "Infographic," TCA Think Tank, http://tcathinktank com/2014/08/16/chinas-city-making-process-investors-power-in-thepeoples-republic.

10 Yuwei Wang, "The Chinese Unit: Persistence of the Collective Urban Model in Beijing", http://issuu.com/projective. 
Limin Hee, "Rethinking Shanghai's Urban Housing," Urban Design International 12, (2-3) (2007).

Sha et al., Shanghai Urbanism at the Medium Scale (Heidelberg: Springer, 2014).

Diagram by author.

John J. Kim, "Designed in Chicago, Made in China."

http://blog.redfin.com/

Diagram by author

\section{Chapter 2}

Yuwei Wang, "The Chinese Unit: Persistence of the Collective Urban Model in Beijing", http://issuu.com/projective.

Limin Hee, "Rethinking Shanghai's Urban Housing."

Y. Sha et al., Shanghai Urbanism at the Medium Scale.

Diagrams by author.

Duanfang Lu and Taylor \& Francis Group, Remaking Chinese Urban Form: Modernity, Scarcity, and Space, 1949-2005 (New York; London: Routledge, 2005).

6 Y. Sha et al., Shanghai Urbanism at the Medium Scale. Ibid.

Duanfang Lu, Remaking Chinese Urban Form.

Clarence Perry, Neighbourhood Unit, www.en.wikipedia.org.

Limin Hee, "Rethinking Shanghai's Urban Housing."

Y. Sha et al., Shanghai Urbanism at the Medium Scale.

Xinhua, "Guiyang defies Beijing with housing incentives," http://www. wantchinatimes.com.

Y. Sha et al., Shanghai Urbanism at the Medium Scale.

14 Tan Jin/Xinhua Press/Corbis, "China in Development," http://www.wwd. com

\section{Chapter 3}


Le Corbusier, Plan Voisin, 1925

Walter Gropius, "From the Block to the Bar," 1925

Clarence Perry, Neighbourhood Unit, www.en.wikipedia.org.

Nicholas Patricios, "Urban Design Principles of the Original Neighbor-

hood Concepts," Urban Morphology 6.1 (2002): 17

Alec Jordan, "Stuyvesant Town-Peter Cooper Village," www.

en.wikipedia.org.

Diagram by author.

United States Geological Survey, "Pruitt-Igoe," www.en.wikipedia.org

8 U.S. Department of Housing and Urban Development, "Pruitt-Igoe," www.en.wikipedia.org

9 Walter Gropius, Concept for spacing of residential slabs, 1929, Ruralise, http://www.ruralise.co.uk/contemporary-farmsteads-3/gropius-density-

diagram.

Bing Maps, https://www.bing.com/maps.

Diagram by author.

Walter Gropius, "From the Block to the Bar," 1925

13 Diagram by author

\section{Chapter 4}

Planundrum, http://www.planundrum.com

Diagram by author.

Westbank Projects, "Vancouverism vs. Lower Manhattanism: Shaping the High Density City", accessed April 1, 2015, ArchNewsNow, http:// www.archnewsnow.com/features/Feature177.htm.

"The Story of Vancouver", Vancouver Historical Society, http://www.

vancouver-historical-society.ca/blog/introduction/vi-the-aesthetic-socialand-cultural-development-of-the-city/

Calthorpe Associates, "Yuelai Eco-City", accessed March 30, 2015,

http://www.calthorpe.com/yuelai.

$6 \quad$ Calthorpe Associates, "Chenggong New Town", accessed March 30,

2015, http://www.calthorpe.com/chenggong 
Calthorpe Associates, "Liangjiang New District Transit Oriented Districts

Plan", Congress for the New Urbanism, accessed March 30, 2015

https://www.cnu.org/resources/projects/liangjiang-new-district-transit-

oriented-districts-plan-2013

Kjersti Monson, "String Block vs Superblock Patterns of Dispersal in

China", Architectural Design 78, (1) (2008): 48.

9 Y. Sha et al., Shanghai Urbanism at the Medium Scale.

10 Ibid.

11 Diagram by author.

12 Diagram by author

\section{Chapter 5}

1-21 Diagrams by author 